The State of Aging and Health
in America
2007

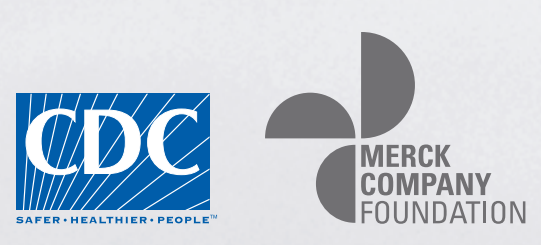




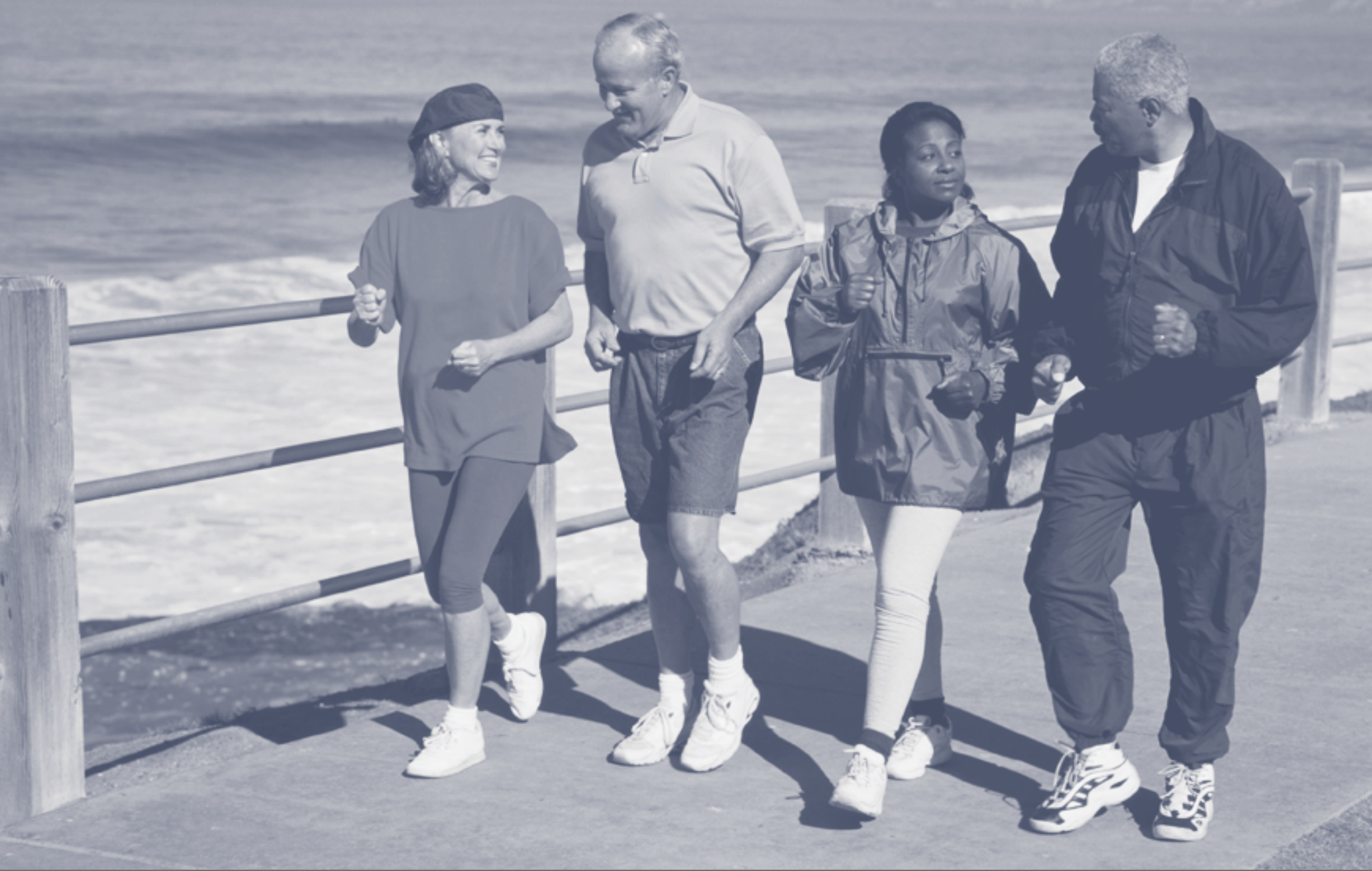

\section{The State of Aging and Health in America 2007}

The State of Aging and Health in America 2007 is the fifth volume of a series that presents a snapshot of the health and aging landscape in the United States and other regions of the world. This series presents the most current information and statistics, often specifically commissioned for the report, on the health of older adults. The State of Aging and Health reports are supported by The Merck Company Foundation and produced with various partner organizations that are recognized as leaders in the aging field.

\section{Suggested Citation:}

Centers for Disease Control and Prevention and The Merck Company Foundation.

The State of Aging and Health in America 2007.

Whitehouse Station, NJ: The Merck Company Foundation; 2007.

Available at www.cdc.gov/aging and www.merck.com/cr

An interactive version of The State of Aging and Health in America 2007 report is available online at www.cdc.gov/aging 


\section{Forward}

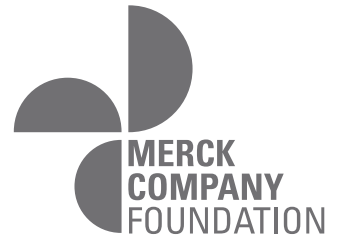

“Entirely supported by Merck \& Co., Inc., The Merck Company Foundation is a philanthropic organization that strives to enhance the health and well-being of people around the world. As demonstrated by Merck's century-long commitment to the Merck Manuals, this includes getting health information into the hands of everyone who needs it. The State of Aging and Health in America 2007 is part of that effort. The report presents information and recommendations to help older Americans live not just longer but better lives. In terms of transforming the promise of active aging into reality in America, this publication shows us where we are, where we must go and, through its thoughtful calls to action, how to get there."

- Steven B. Kelmar, President, The Merck Company Foundation

"The aging of the U.S. population is one of the major public health challenges we face in the 21st century. One of CDC's highest priorities as the nation's health protection agency is to increase the number of older adults who live longer, high-quality, productive, and independent lives. The State of Aging and Health in America 2007 is an important tool for supporting this goal. This report identifies key older adult health issues, assesses our success in addressing them, and provides suggestions and resources for further action. CDC values its role as a contributor to this report and looks forward to working with our partners to achieve better health and quality of life for all older Americans."

- Julie Louise Gerberding, MD, MPH, Director, Centers for Disease Control and Prevention, U.S. Department of Health and Human Services 


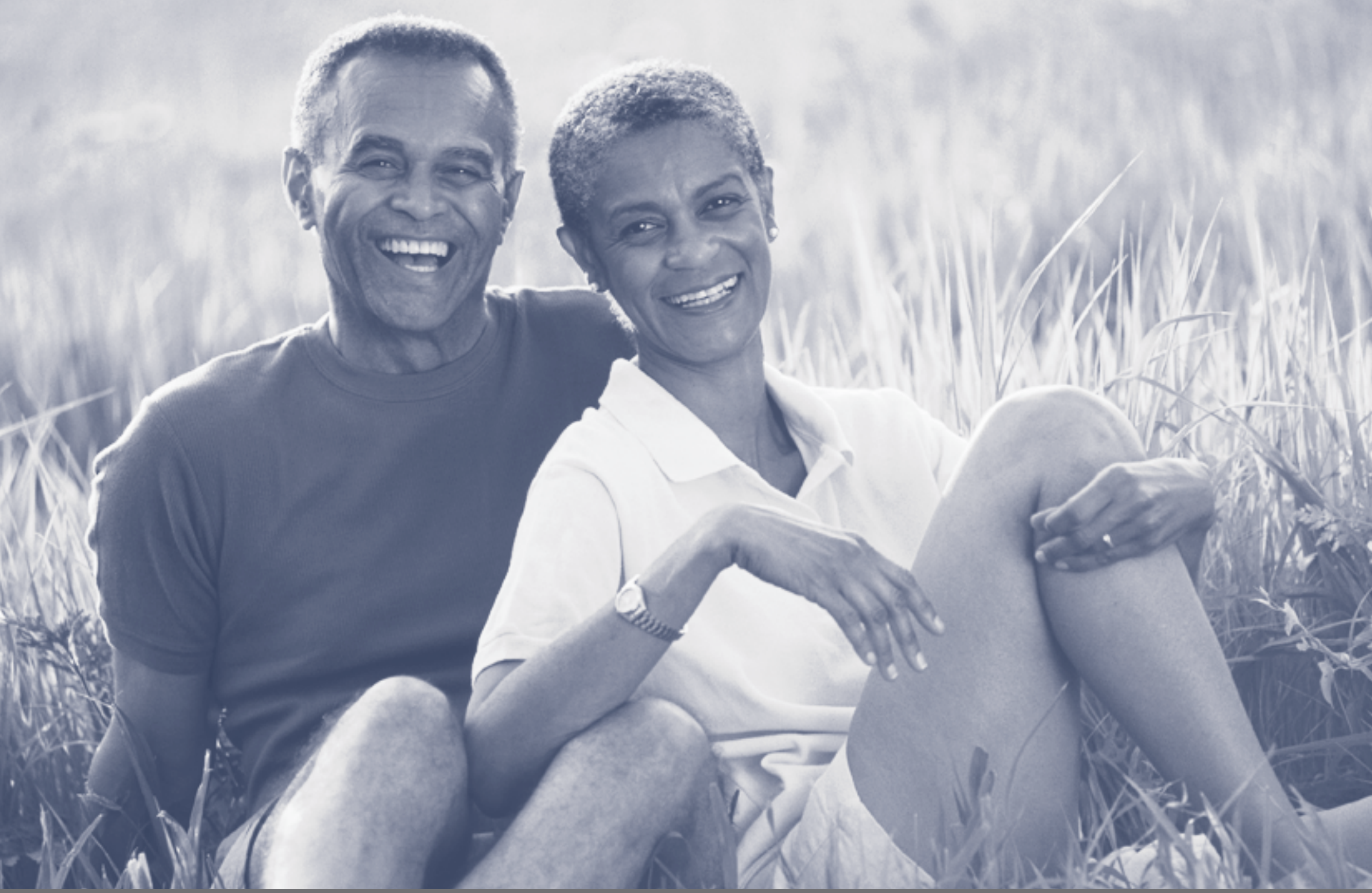

\section{Executive Summary}

Twentieth-century advances in protecting and promoting health among older adults have given us many opportunities for overcoming the challenges of an aging society. The health indicators presented in The State of Aging and Health in America 2007 highlight these opportunities. By working to meet the goals for each of these key indicators, our nation can help to ensure that all of its citizens can look forward not just to living longer, but to living well. 
The State of Aging and Health in America 2007 provides a snapshot of our nation's progress in promoting the health and well-being of older adults and reducing behaviors that contribute to premature death and disability. The report also highlights three key areas that can significantly improve the quality of life for older adults: reducing falls, maintaining cognitive health, and improving end-of-life care.

\section{Demographic changes create an urgent need}

Improved medical care and prevention efforts have contributed to dramatic increases in life expectancy in the United States over the past century. They also have produced a major shift in the leading causes of death for all age groups, including older adults, from infectious diseases and acute illnesses to chronic diseases and degenerative illnesses. Currently, about $80 \%$ of older Americans are living with at least one chronic condition.

The growth in the number and proportion of older adults is unprecedented in the history of the United States. Two factors — longer life spans and aging baby boomers - will combine to double the population of Americans aged 65 and older during the next 25 years. By 2030, there will be 71 million American older adults accounting for roughly $20 \%$ of the U.S. population.

America's older adult population also is becoming more racially and ethnically diverse. At the same time, the health status of racial and ethnic minorities lags far behind that of non-minority populations. The burden of many chronic diseases and conditions - especially high blood pressure, diabetes and cancer — varies widely by race and ethnicity. Data from the 2004 National Health Interview Survey (NHIS) indicated that $39 \%$ of non-Hispanic white adults aged 65 years or older reported very good or excellent health, compared with $24 \%$ of non-Hispanic blacks and $29 \%$ of Hispanics. ${ }^{(5)}$

\section{There is a strong economic incentive for action}

The cost of providing health care for an older American is three to five times greater than the cost for someone younger than 65 . As a result, by 2030 , the nation's health care spending is projected to increase by $25 \%$ due to these demographic shifts.

\section{More than one-third of U.S. deaths are preventable}

Three behaviors — smoking, poor diet, and physical inactivity - were the root causes of almost $35 \%$ of U.S. deaths in 2000. These behaviors are risk factors that often underlie the development of the nation's leading chronic disease killers: heart disease, cancer, stroke, and diabetes.

The above statistics highlight the need to focus on improving the health of older adults by encouraging them to adopt healthier behaviors and obtain regular health screenings that can reduce the risk for many chronic diseases, help decrease health disparities, and lower health care costs.
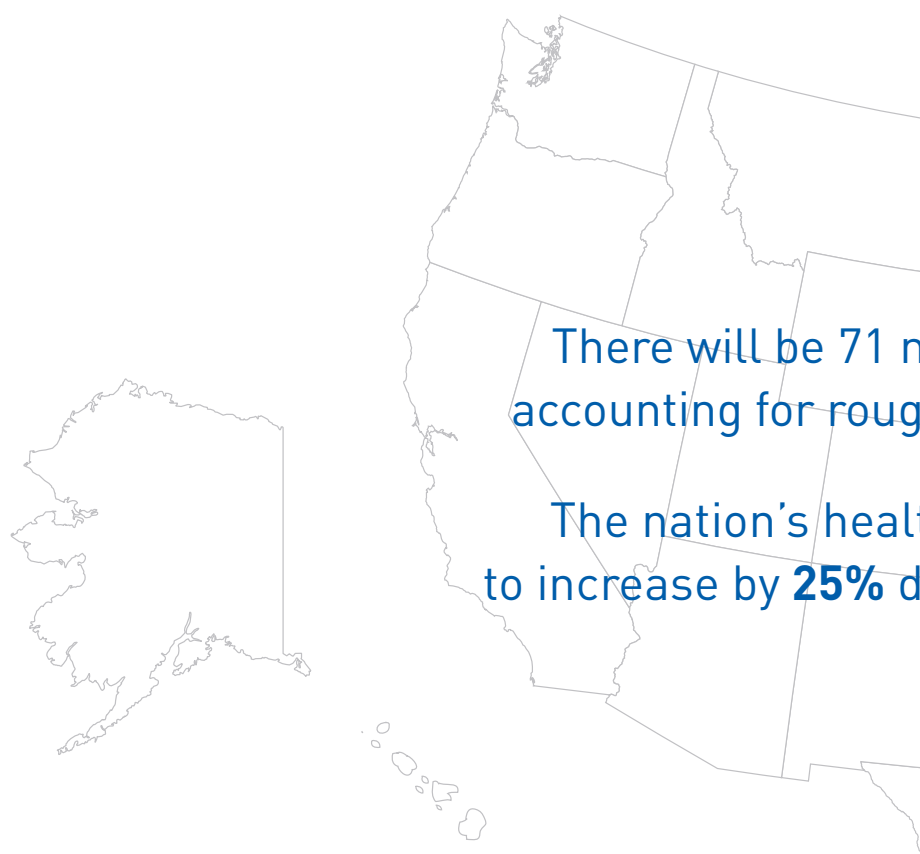
accounting for roughly $20 \%$ of the U.S. population

The nation's health care spending is projected to increase by $\mathbf{2 5 \%}$ due to these demographic shifts. 


\section{The Report Cards}

The National Report Card on Healthy Aging (page 9) reports on 15 indicators of older adult health, 11 of which are identified by the Healthy People 2010 initiative of the U.S. Department of Health and Human Services. Those 15 indicators are grouped into four areas: Health Status, Health Behaviors, Preventive
Care and Screening, and Injuries. The report also assigns a "met" or "not met" grade (based on 2003 or 2004 data) to those indicators with specific Healthy People 2010 targets. Taken together, these indicators present a comprehensive picture of older adult health in the United States.

The United States has met 4 of the 11 Healthy People 2010 targets - six years ahead of schedule . . .

- Mammograms within past two years

- Colorectal cancer screenings

- Cholesterol checked within the past five years

- People currently smoking
$(75 \%$ vs. goal of $70 \%)$

$(63 \%$ vs. goal of $50 \%)$

$(90 \%$ vs. goal of $80 \%)$

$(9 \%$ vs. goal of $12 \%)$

But has more room for improvement on the remaining Healthy People 2010 targets ...

- Oral Health: Complete tooth loss

- No leisure time physical activity in past month

- Obesity

- Flu vaccine in past year

- Pneumonia vaccine

- Hip fracture hospitalizations per 100,000 persons

- Eating at least five fruits and vegetables daily
(21\% vs. goal of $20 \%$ )

(32\% vs. goal of $20 \%)$

(20\% vs. goal of $15 \%$ )

$(68 \%$ vs. goal of $90 \%)$

$(65 \%$ vs. goal of $90 \%)$

(558 men/1113 women vs. goal of 474 men/416 women)

(The 2010 nutrition target is segmented into multiple goals for different fruits and vegetables, but the current national percentage of $29.8 \%$ is below all of the 2010 nutrition targets.)
The State-by-State Report Card on Healthy Aging (page 22) ranks the 50 states and the District of Columbia (D.C.) for each health indicator, and assigns each a grade according to its performance relative to the other states. Hawaii, for example, was most often ranked among the five top performing states (eight times), while Kentucky was most often ranked in the bottom five (nine times).
Variation among states can be significant. For example, Connecticut ranked first in the oral health indicator, with only $12.4 \%$ of older adults having lost all of their teeth, while West Virginia ranked last in this category, with $42.9 \%$ of older adults experiencing complete tooth loss.

\section{The vast majority of states are well ahead of schedule on four health indicators ...}

- Mammograms

- Colorectal cancer screenings

- Cholesterol screenings

- People currently smoking
46 states and D.C. met the 2010 target

49 states and D.C. met the 2010 target

50 states and D.C. met the 2010 target 46 states and D.C. met the 2010 target

Yet all states have more work to do on the other indicators ...

- No leisure time physical activity in past month

- Flu vaccine in past year

- Pneumonia vaccine

- Eating fruit and vegetables daily

- Obesity

- Oral Health: complete tooth loss

- Hip fracture hospitalizations per 100,000 persons
0 states met the 2010 target

0 states met the 2010 target

0 states met the 2010 target

0 states met the 2010 target

3 states met the 2010 target

21 states and D.C. met the 2010 target

No data for states available 


\section{Opportunities for Enhancing Quality of Life}

The State of Aging and Health in America 2007 report focuses on several areas of concern that, if effectively addressed, will significantly improve the quality of life for older adults.

\section{Preventing cognitive decline;}

Addressing end-of-life issues (page 5)

As more and more Americans reach the age of 65, society is increasingly challenged to help them grow old with dignity and comfort. The State of Aging and Health in America 2007 report identifies the prevention of cognitive decline and alleviation of end-of-life suffering as key areas where the public health arena can help make significant improvements in quality of life. Meeting these challenges is critical to ensuring that baby boomers can look forward to their "golden years." The report states that through research and education about cognitive health, and public education about end-of-life issues, both challenges can be effectively addressed.

\section{Reducing falls among older adults (page 26)}

Falls are the leading cause of injury deaths and the most common cause of injuries and hospital admissions for trauma among adults aged 65 or older. Fall-related injuries cause significant mortality, disability, loss of independence, and early admission to nursing homes. Fractures are among the most prevalent fall injuries. Each year, 360,000-480,000 older adults sustain fall-related fractures. Fall-related injuries also create a significant financial burden for the United States.

Research has shown that many falls can be prevented by addressing personal risk factors (such as monitoring medications, improving balance, and correcting vision problems) and environmental risk factors (such as removing tripping hazards and installing safety features such as handrails).

\section{Innovative Approaches}

Many states and communities have developed innovative ways to ensure that key information on the health of older adults is readily available to those who need it for planning programs, setting priorities, and tracking trends. This report highlights two such programs:

- Orange County, California's Condition of Older Adults report series - a comprehensive, user-friendly snapshot of the general health and well-being of the county's older residents.

- The Missouri Senior Report — a document that provides county-level data and other information to help state and local policy makers, service providers, and seniors themselves plan for future needs.

\section{»CALLS TO ACTION »}

The State of Aging and Health in America 2007 report presents several Calls to Action intended to encourage individuals, professionals, and communities to take specific steps to improve the health and well-being of older adults. They include the following recommendations:

» Address health disparities among older adults, particularly in racial and ethnic minority populations. (page 3)

»Encourage people to communicate their wishes about end-of-life care. (page 6)

» Improve the oral health of older adults. (page 11)

» Increase physical activity among older adults by promoting environmental changes. (page 12)
» Increase adult immunizations, particularly in racial and ethnic minority populations. (page 15)

» Increase screening for colorectal cancer. (page 16)

» Prevent falls, a leading cause of hospitalization and injury deaths among older adults. (page 32)

The State of Aging and Health in America 2007 report highlights the need to maintain the progress made in several health indicators, while increasing efforts to meet the goals on other equally crucial health issues. The key to improving the health and quality of life for all older Americans, the report shows, will be collaboration between multiple and diverse groups on the national, state and local levels, including members of the public, health care providers, government agencies and community groups. 



\section{Table of Contents}

An Introduction to the Health of Older Americans................................................. 2

» CALL TO ACTION » Addressing health disparities among older adults................. 3

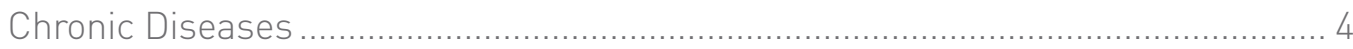

New Opportunities for Public Health in Aging .................................................... 5

» CALL TO ACTION » Communicating wishes about end-of-life .............................. 6

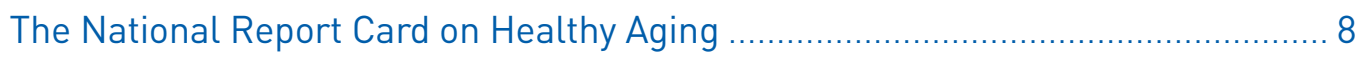

» CALL TO ACTION » Improving the oral health of older Americans ..................... 11

»CALL TO ACTION » Encouraging physical activity by promoting changes to the physical environment

» CALL TO ACTION » Increasing adult immunization in

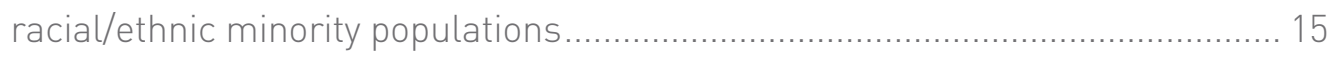

» CALL TO ACTION » Increasing screening for colorectal cancer .......................... 16

The State-by-State Report Card on Healthy Aging ........................................... 20

Using Data for Action at the State and Local Levels .......................................... 25

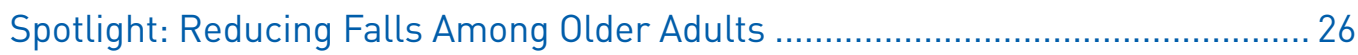

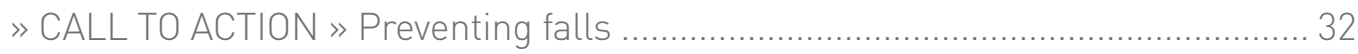

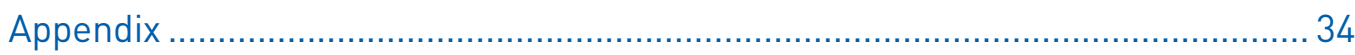

Acknowledgements ............................................................. Inside Back Cover 


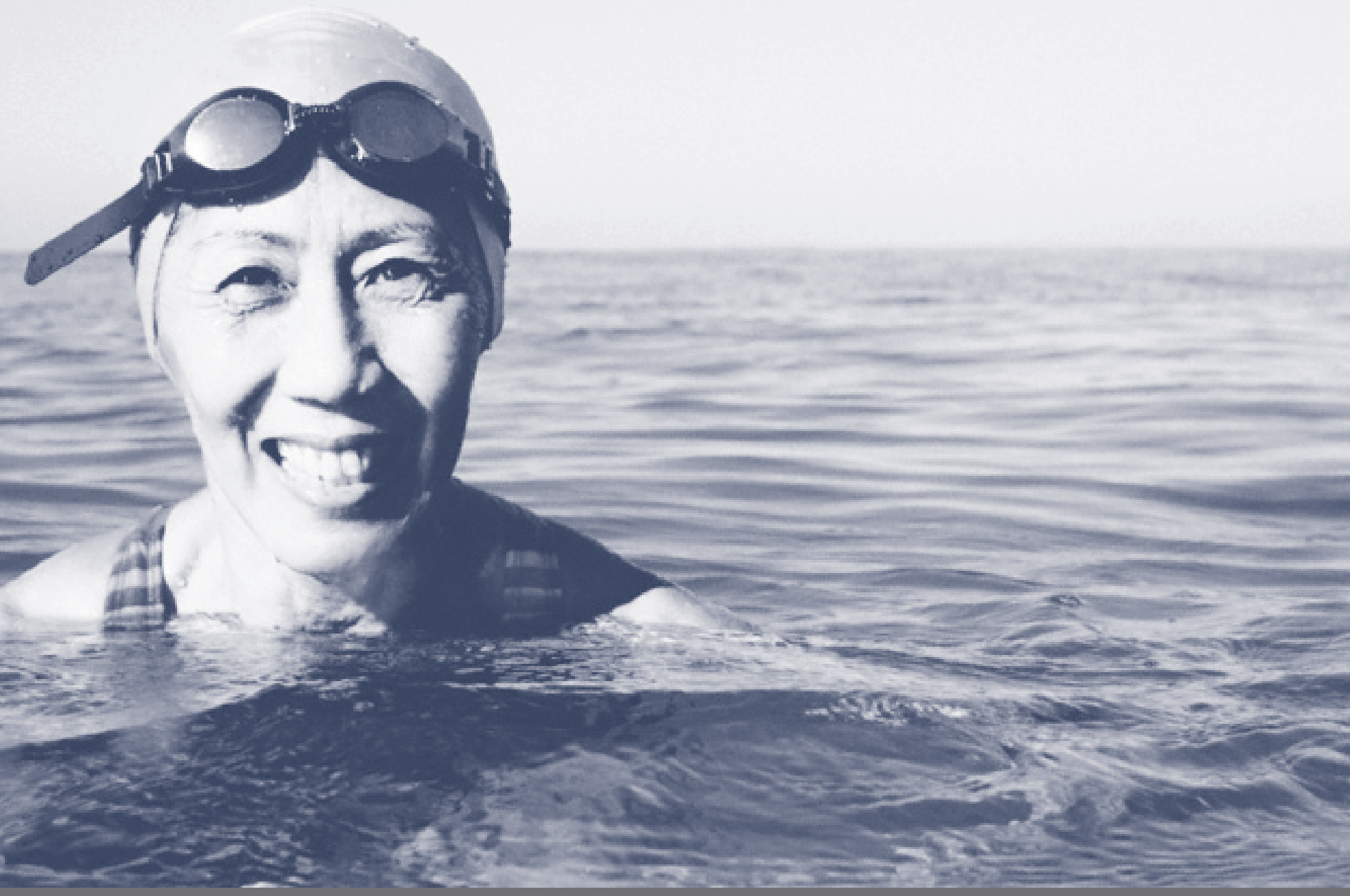

\section{An Introduction to the Health of Older Americans}

The U.S. Population Is Aging ...

The current growth in the number and proportion of older adults living in the United States is unprecedented in our nation's history. Two factors - longer lives and aging baby boomers - will double the population of Americans aged 65 or older during the next 25 years. Life expectancy in the U.S. has increased from 47 years for Americans born in 1900 to 77 years for those born in 2001'11; and baby boomers - those born between 1946 and 1964 - will begin to reach age 65 in 2011. By 2030, the number of older Americans is expected to reach 71 million, or roughly $20 \%$ of the U.S. population. ${ }^{[2,3]}$ 


\section{... and Becoming More Racially and Ethnically Diverse}

In $2003,83 \%$ of older adults in the United States were non-Hispanic white; $8 \%$ were non-Hispanic black; $6 \%$ were Hispanic; and 3\% were Asian. By 2030, the changing face of older adults in the United States will be evident: only $72 \%$ of this population will be non-Hispanic white; $11 \%$ will be Hispanic; $10 \%$ will be black; and 5\% will be Asian (Figure 1).(4)

\section{»CALL TO ACTION »}

\section{Addressing Health Disparities Among Older Adults}

An underlying theme of this report is the growing problem of racial and ethnic health disparities among older adults. Two factors continue to increase the urgency of this problem - the dramatic aging of the U.S. population and the growing proportion of racial and ethnic minority groups.

The health status of racial and ethnic minorities of all ages lags far behind that of non-minority populations. For a variety of reasons, older adults may experience the effects of health disparities more dramatically than any other population group. For one, older adults are more likely to have chronic illness and require frequent contact with the health care system. Also, many live in poverty, making access to health care a challenge. The care of older adults who are chronically ill, poor, and members of an ethnic community is an increasingly urgent health priority.

A major effort to help address these health disparities is the Racial and Ethnic Approaches to Community Health (REACH 2010) Program, which supports community-based coalitions in the design, implementation, and evaluation of innovative strategies to reduce or eliminate health disparities among racial and ethnic minorities. These groups include: African Americans; Hispanic Americans; American Indians; Alaska Natives; Asian Americans; and Pacific Islanders.

One example of a successful REACH 2010 Program is the Latino Education Project (LEP), in the Corpus Christi, Texas area, which targets midlife and older Latinos - a population that suffers disproportionately from diabetes and its complications. The need for assistance in these small, rural, and isolated communities is great. Approximately $80 \%$ to $95 \%$ of the residents are Hispanic; and almost $50 \%$ are aged 60 or older. The depressed economy and chronic unemployment rates that characterize these communities perpetuate poverty from generation to generation.
FIGURE 1

The U.S. Population aged 65 years or older is growing more diverse

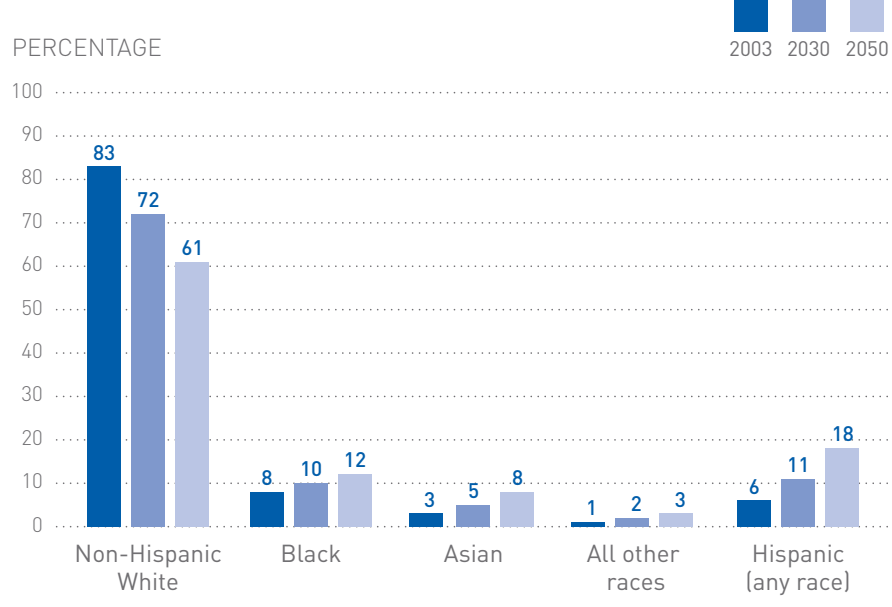

Source: U.S. Census Bureau, 2004
This area has been classified as medically underserved for decades, and the high cost of health care, lack of access to health insurance, and limited community resources contribute significantly to health disparities.

LEP Program activities focus on enabling and mobilizing key community institutions and organizations to respond to the diabetes crisis among midlife and older Hispanics. Communitywide health forums bring together health care providers, advocates, elected officials, radio, television and newspaper representatives, and local leaders to identify the best strategies for the prevention, early diagnosis, and management of diabetes. Small study circles allow for personalized attention, focusing on individual behavioral change through the selection of healthier foods, promoting and facilitating physical activity, and mobilizing informal support networks. Lay health educators (Promotores de Salud) use their leadership skills to assist communities and individual participants to access resources on their own. The educators provide case management that leads to healthier behaviors, better health, and improved management of diabetes. As a result of these activities, LEP participants have increased their levels of physical activity and consumption of water, fruits, and vegetables, as well as improved communication with their health care providers.

REACH 2010 Programs are fostering community commitment and active participation of seniors, stakeholders, and state and local officials - two key strategies for improving health and access to health care among older adult communities of color.

For more information about these programs, visit http://www.cdc.gov/reach2010. 


\section{Chronic Diseases}

\section{Are the Leading Causes of Death}

Improved medical care and prevention efforts have contributed to dramatic increases in life expectancy in the United States during the past century. However, they also have produced a major shift in the leading causes of death for all age groups, including older adults, from infectious diseases and acute illnesses to chronic diseases and degenerative illnesses. ${ }^{(2)}$ In 2002, the top three causes of death for U.S. adults aged 65 or older were heart disease ( $32 \%$ of all deaths), cancer (22\%), and stroke (8\%). These accounted for $61 \%$ of all deaths in this age group (Figure 2). ${ }^{(5)}$

\section{FIGURE 2}

Chronic diseases were the leading causes of death among U.S. adults aged 65 or older in 2002

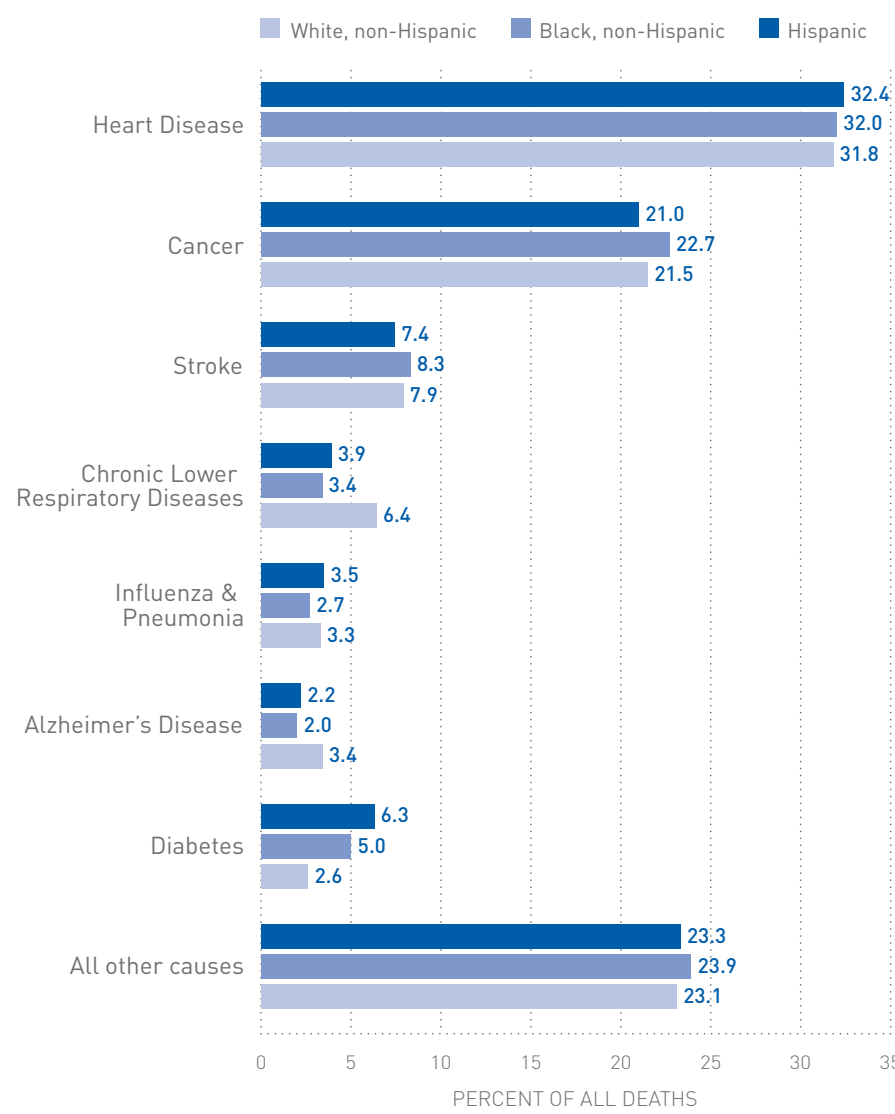

Source: CDC, National Center for Health Statistics,

National Vital Statistics System, 2006

\section{Behavioral Changes Could Improve Health}

The tragedy of these leading killers - heart disease, cancer, and stroke - is that they are often preventable. Although the risk for disease and disability clearly increases with advancing age, poor health is not an inevitable consequence of aging. Three behaviors - smoking, poor diet, and physical inactivity - were the root causes of almost $35 \%$ of U.S. deaths in 2000. ${ }^{(6)}$ These behaviors often underlie the development of the nation's leading chronic disease killers: heart disease, cancer, stroke, and diabetes. Adopting healthier behaviors, such as engaging in regular physical activity, eating a healthy diet, leading a tobacco-free lifestyle, and getting regular health screenings (for example, mammograms and colonoscopies) can dramatically reduce a person's risk for most chronic diseases, including the leading causes of death. ${ }^{(7)}$

\section{Chronic Diseases Cause Pain and Disability and Increase Health Care Costs}

Death is only part of the picture of the burden of chronic diseases among older Americans. These conditions can cause years of pain, disability, and loss of function and independence before resulting in death. Currently, at least $80 \%$ of older Americans are living with at least one chronic condition, and 50\% have at least two. ${ }^{(2)}$ In addition, the burden of many chronic diseases and conditions — especially high blood pressure, diabetes, and cancer — varies widely by race and ethnicity (Figure 3 ).

FIGURE 3:

Prevalence of chronic conditions among adults aged 65 years or older varied by race/ethnicity in 2002-2003

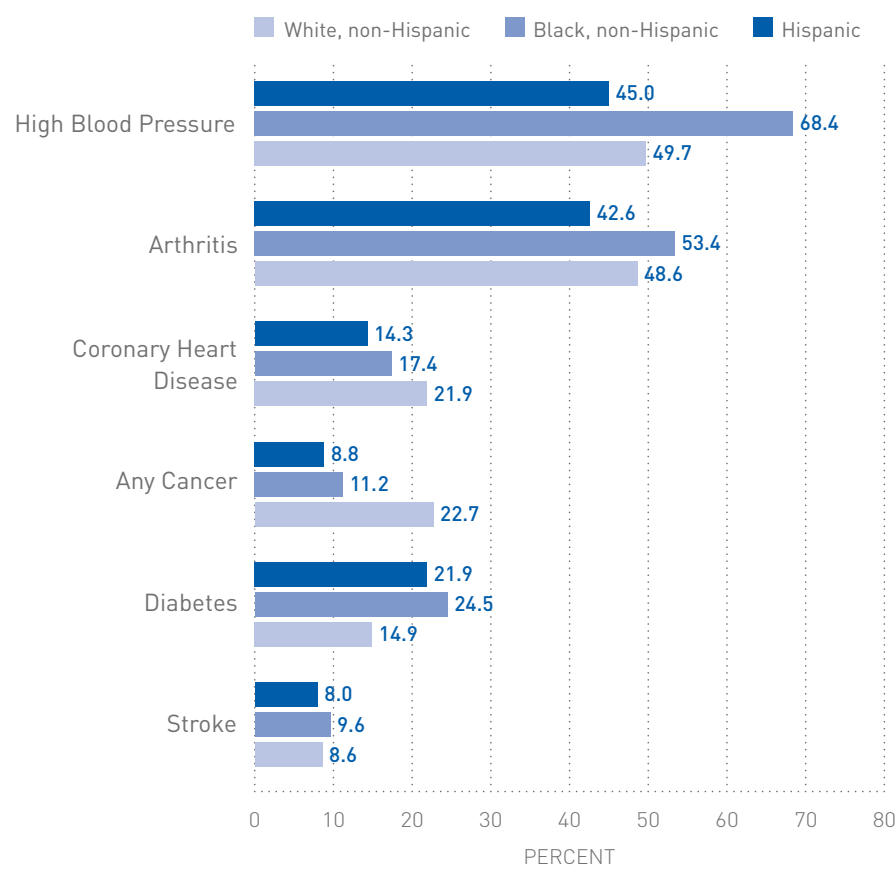

Source: CDC, National Center for Health Statistics, National Health Interview Survey, 2006. 


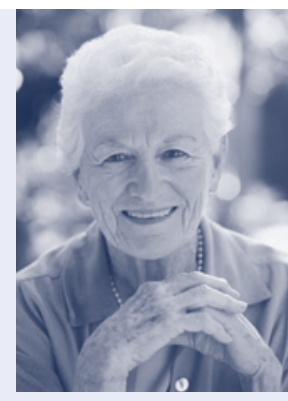

\section{Arthritis}

One example of the far-reaching impact of chronic diseases is arthritis and other rheumatic conditions, which currently affect almost 43 million U.S. adults. Arthritis and related conditions are associated with chronic pain and functional limitations and represent the leading cause of disability in the United States. ${ }^{(8)}$ The aging of the U.S. population, in conjunction with the obesity epidemic, will only increase the impact of arthritis. The number of adults with arthritis is projected to increase to 67 million by 2030 , and although $54 \%$ of this group will be aged 65 or older, working-age adults (45-64 years) also will be seriously affected, accounting for almost one-third of cases. ${ }^{(8)}$

The nation's health care costs, which are already high, also will be affected by the increasing number of Americans aged 65 or older. Currently, more than two-thirds of health care costs are for treating chronic illnesses; among older Americans, almost $95 \%$ of health care expenditures is for chronic diseases. ${ }^{(9)}$ The cost of providing health care for one person aged 65 or older is three to five times greater than the cost for someone younger than $65 .^{(2)}$ By 2030 , health care spending will increase by $25 \%$ largely because the population will be older, without taking into account inflation or the higher costs of new technologies. ${ }^{(10)}$ Medicare spending has grown about ninefold in the past two decades, from $\$ 37$ billion in 1980 to $\$ 336$ billion in 2005. ${ }^{(11)}$

The large baby boomer population faces chronic health issues that could increase the likelihood of functional decline as this group ages. In 2003, $41.8 \%$ of adults aged 55-64 were told they had high blood pressure, and 56.6\% did not meet recommended guidelines for physical activity. In $2004,12.5 \%$ of adults in this age group were told they had diabetes. ${ }^{(12)}$ These statistics highlight the need for the nation's public health community to focus more on opportunities to prevent or delay disease and disability for older adults and to stem rising health care costs.

\section{Chronic Diseases Diminish Quality of Life for Older Adults}

Among older adults, chronic diseases can lead to limitations in daily activities and thus often reduce health-related quality of life for seniors. The percentage of older U.S. adults who report very good or excellent health decreases with age, and the percentages are even lower for some minority populations. Data from the 2004 National Health Interview Survey (NHIS) indicated that $39 \%$ of non-Hispanic white adults aged 65 years or older reported very good or excellent health, compared with $24 \%$ of non-Hispanic blacks and $29 \%$ of Hispanics. ${ }^{(5)}$

\section{New Opportunities for Public Health in Aging}

As more and more Americans reach the age of 65 , society is increasingly challenged to help them grow old with dignity and comfort. Two key challenges that are new to the public health arena - although they have long been the target of health care and aging services professionals - are preventing and treating cognitive decline and addressing end-of-life issues. Meeting these challenges is critical to ensuring that baby boomers can look forward to their later years.

\section{Healthy Brain Initiative: A Public Health Roadmap to Maintaining Cognitive Health}

Recent research is proving several myths about cognition to be incorrect - notably, the beliefs that aging is a time of irreversible mental decline and that dementia is universal and inevitable. ${ }^{(13)}$ As such, researchers and health professionals have begun to focus on opportunities to maintain or possibly improve cognitive health. Cognitive health means more than just the absence of diseases of the brain. Cognitive health refers to "a combination of mental processes we commonly think of as 'knowing' and includes the ability to learn new things, intuition, judgment, language, and remembering. At all ages, having a clear and active mind is important, and is particularly important for older adults because it can mean the difference between dependence and independent living." (14)

Opportunities to maintain cognitive health, and possibly prevent cognitive decline, are growing as scientists gain a

Cognitive health is not static. When problems occur, they can range from mild cognitive impairment to severe dementia. Dementia is not a single disease but a collective term for numerous brain disorders that affect intellectual and social function and interfere with activities of daily living. In 2002, approximately 2.5 million Americans had a diagnosis of dementia. By 2030, the number of Americans with a confirmed diagnosis of dementia is expected to more than double to 5.2 million (D.J. Thurman, MD, CDC, unpublished data, 2006). 
better understanding of the factors that increase the risk of developing cognitive impairment. Based on recent scientific discussions, the following set of conditions and behaviors are related to cognitive decline: high blood pressure; elevated cholesterol; diabetes; overweight and obesity; smoking; and physical inactivity.

Although current science linking cognitive decline and dementia is not clear, the work on maintaining cognitive function may hold future possibilities for preventing dementias such as Alzheimer's disease.

Major societal benefits from basic and clinical research surrounding cognitive health will not be achieved unless these findings can be translated into real-world practice. Promoting and protecting cognitive health require new collaborations and investments to advance science and its applications in this area. The public health community has responded to this need with the following initial activities:

- Developing a national roadmap of recommendations concerning public health opportunities to promote and protect cognitive health. CDC and the Alzheimer's Association share leadership for the development of the roadmap and, through this process, are fostering critical partnerships with other federal, state, and local organizations concerned with cognitive health.

- Supporting the Alzheimer's Association as it expands its focus to include the prevention of dementia and as it develops new community-based programs to inform special population groups about cognitive health.

- Assessing the public's perceptions about cognition and determining how best to inform the public about cognitive health and associated risk factors for cognitive

\section{»CALL TO ACTION »}

\section{Communicating Wishes About End-Of-Life}

Many people have considered whom they want to speak for them should they become unable to make health-related decisions for themselves. Unfortunately, this information is often unknown to family members and health care providers. Health care directives filed with one's will and other legal papers rarely find their way into medical care settings, and family members are frequently called upon to make decisions on behalf of a loved one without having an understanding of his or her preferences. To avoid this situation, conversations about end-of-life decisionmaking should take place with family members and health care providers, preferably prior to the onset of a serious illness. decline through a national collaboration known as the Healthy Aging Research Network of the Prevention Research Centers.

\section{Addressing End-of-Life Issues}

Major advances in public health and medicine during the past century have shifted the leading cause of death from infectious disease to chronic disease, resulting in a longer lifespan. As a result, most of us alive today will die at an advanced age following a period of chronic illness. At the same time, with innovations in medical technology and treatment, quality of life and of dying have become increasingly important societal concerns.

While end-of-life issues have steadily gained recognition in the health care system as an important area to address, the public health community has only recently come to recognize this as an area requiring its involvement. ${ }^{(15)}$ End-of-life issues share characteristics that are similar to other public health priorities, namely a substantial burden (e.g., universal incidence), a major impact on the individual and family members (e.g., effect on caregiver health), financial costs for individuals as well as society, and the potential to prevent suffering associated with the dying process.

There are substantial opportunities for public health professionals to help in addressing end-of-life issues. Recent initiatives involving diverse stakeholders have identified a series of priorities for the public health community regarding end-of-life issues. ${ }^{(16)}$ Based on this effort, the critical next steps include:

- Identifying end-of-life surveillance measures

- Educating the public health community about end-of-life issues and public health's role in improving end-of-life experiences

- Providing public education regarding end-of-life options, such as hospice care, palliative care, and advance directives.

Having these conversations is the best way to protect one's autonomy in many unpredictable situations. Such discussions also allow one to reflect on his or her life and values and share this legacy with family and loved ones. Yet many find it difficult to begin such discussions. To get started, several resources exist to help foster meaningful conversations and practical planning for end-of-life care. Caring Conversations ${ }^{T M}$ is one such resource, offering workbooks (in English and Spanish) that include health care directives and a durable power of attorney for health care decisions. 
Our growing knowledge of critical factors that help to protect and promote health has led to vast opportunities for overcoming the health challenges facing the aging population. The health indicators discussed in the following chapters point the way to these opportunities, and how we will meet the challenges of health disparities, widespread chronic disease, and increasing health care costs. By working to meet the goals for each of these key indicators, our nation can help to ensure that all of its citizens can look forward not just to living longer, but to living well.

\section{Selected Additional Resources}

\section{Health Disparities}

- American Medical Association, Eliminating Health Disparities http://www.ama-assn.org/ama/pub/category/7639.html

- CDC, Office of Minority Health and Health Disparities http://www.cdc.gov/omh

- CDC, REACH 2010 Program http://www.cdc.gov/reach2010

- National Institutes of Health (NIH), National Center on Minority Health and Health Disparities http://ncmhd.nih.gov

- U.S. Department of Health and Human Services, Office of Minority Health http://www.omhrc.gov

\section{Brain Health}

- Alzheimer's Association http://www.alz.org

- AARP, Healthy Brain http://www.aarp.org/health/brain

- CDC, Healthy Aging Program http://www.cdc.gov/aging

- $\quad \mathrm{NIH}$, National Institute on Aging http://www.nia.nih.gov/Alzheimers

End-of-Life

- AARP, End-of-Life Resources http://www.aarp.org/families/end_life

- Center for Practical Bioethics, Caring Conversations ${ }^{\circledR}$ http://www.practicalbioethics.org/cpb.aspx?pglD=886

- Center for Practical Bioethics, Aging and End-of-Life Care http://www.practicalbioethics.org/cpb.aspx?pglD=885

- National Hospice and Palliative Care Organization http://www.nhpco.org

- Robert Wood Johnson Foundation, A Record of Accomplishment in End-of-Life Care http://www.rwjf.org/newsroom/featureDetail. jsp? featurelD=886\&type $=3$

- Robert Wood Johnson Foundation, Means to a Better End: A Report on Dying in America http://www.rwjf.org/files/publications/other/meansbetterend.pdf

\section{References}

1. Centers for Disease Control and Prevention. Health, United States, 2003. Hyattsville, MD: U.S. Department of Health and Human Services, National Center for Health Statistics; 2003.

2. Centers for Disease Control and Prevention. Public health and aging: trends in aging - United States and worldwide. Morbidity and Mortality Weekly Report 2003;52(06):101-106.

3. Wan H, Sengupta M, Velkoff VA, DeBarrow KA, U.S. Census Bureau. 65+ in the United States: 2005 (Current Population Reports). Washington DC: U.S. Government Printing Office; 2005. Available at http://www.census.gov/prod/2006pubs/p23-209.pdf laccessed April 25, 2006).

4. National Institute on Aging. Dramatic changes in U.S. aging highlighted in new census [press release]. Bethesda, Maryland: National Institutes of Health; March 9, 2006.Available at www.nih. gov/news/pr/mar2006/nia-09.htm laccessed August 18, 2006).

5. Centers for Disease Control and Prevention. National Center for Health Statistics Data Warehouse. Trends in Health and Aging. Available at http://www.cdc.gov/nchs/agingact.htm laccessed June 5, 2006).

6. Mokdad AH, Marks JS, Stroup DF, Gerberding JL. Actual causes of death in the United States, 2000. JAMA 2004;291(10):1238-1245.

7. Blackman DK, Kamimoto LA, Smith SM. Overview: surveillance for selected public health indicators affecting older adults-United States. MMWR Surveillance Summaries 1999;48(No. SS-8):1- 6.

8. Hootman JM, Helmick CG. Projections of U.S. prevalence of arthritis and associated activity limitations. Arthritis and Rheumatism 2006;54(1):226-229.

9. Hoffman C, Rice D, Sung HY. Persons with chronic conditions: their prevalence and costs. JAMA 1996;276(18):1473-1479.

10. Agency for Healthcare Research and Quality, Centers for Disease Control and Prevention. Physical Activity and Older Americans: Benefits and Strategies. June 2002. Available at http://www.ahrq. gov/ppip/activity.htm (accessed May 21, 2006).

11. Medicare Payment Advisory Commission. A data book: healthcare spending and the Medicare program. June 2006. Section 1: National health care and Medicare spending. Available at http://www.medpac. gov laccessed August 13, 2006).

12. Centers for Disease Control and Prevention. Behavioral Risk Factor Surveillance System (Prevalence Data). Available at http://www.cdc. gov/brfss (accessed June 4, 2006).

13. Alzheimer's Association Medical and Scientific Advisory Council. Alzheimer's Association: 25 years of supporting science and shaping the Alzheimer's research agenda. Alzheimer's \& Dementia: The Journal of the Alzheimer's Association 2005;1(1):11-12.

14. Himes, C., Oettinger, E. N., Kenny, D.E. Aging in Stride: Plan ahead, stay connected, keep moving. Washington: Caresource Healthcare Communications, Inc., 2004.

15. Rao JK, Anderson LA, Smith SM. End of Life is a Public Health Issue. American Journal of Preventive Medicine 2002;23(3):215-220.

16. Rao JK, Alongi J, Anderson LA, Jenkins L, Stokes G, Kane M. Development of public health priorities for end-of-life initiatives. American Journal of Preventive Medicine 2005;29(5):453-460. 


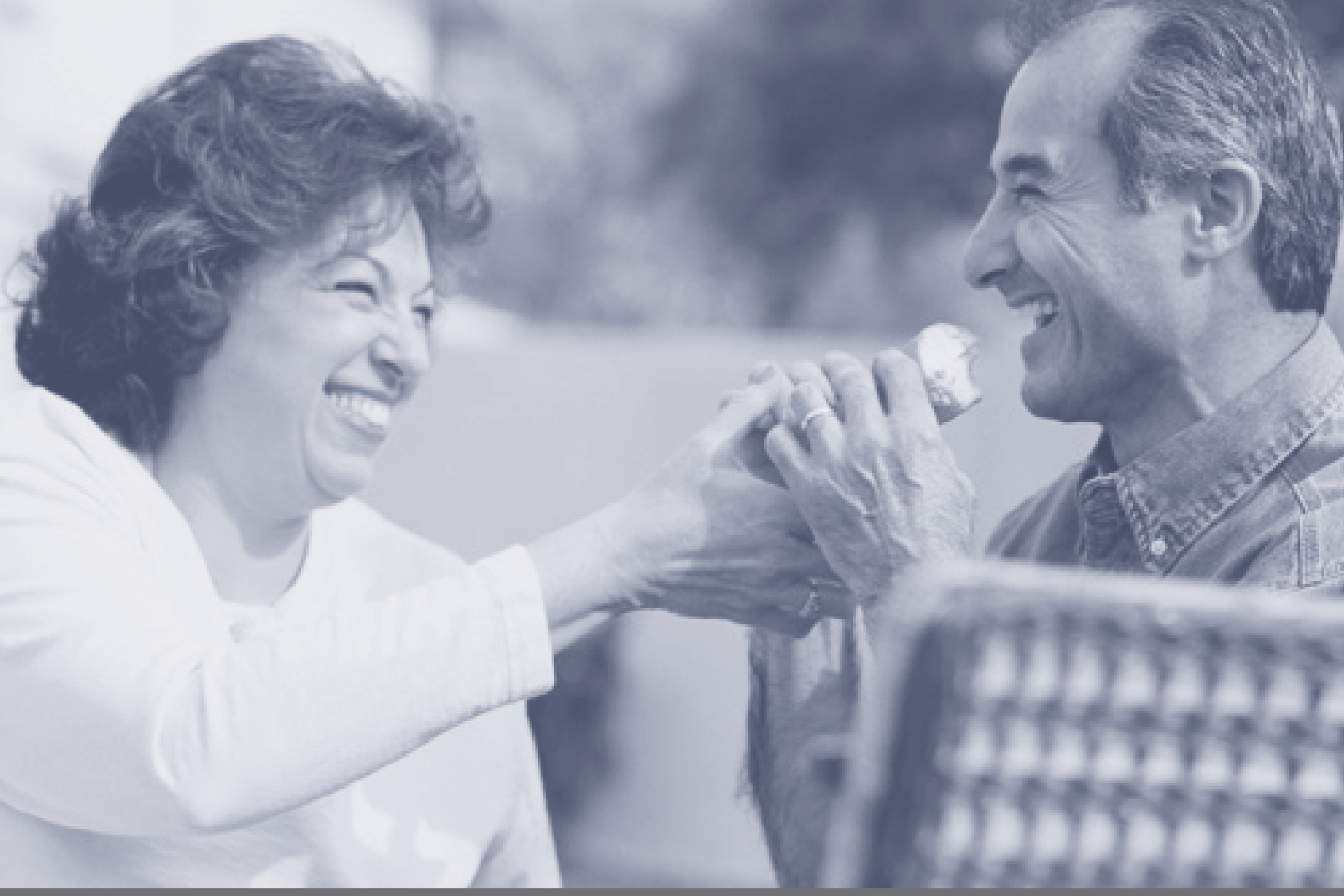

\section{The National Report Card on Healthy Aging}

This section reports on 15 indicators related to the health status of older adults, health behaviors, preventive care and screening, and injuries. These indicators were chosen because they are each modifiable and present a comprehensive picture of older adult health. The report card in Table 1 shows the most current data for the United States for each indicator. It also indicates whether the national Healthy People 2010 target was met. A detailed description of each indicator follows the report card. 
TABLE 1

The National Report Card on Healthy Aging: How Healthy Are Older Adults in the United States?

\section{Summary of Findings:}

- The United States has met targets for 4 of the 11 indicators in this report that are measured by Healthy People 2010: Current smoking, mammogram within past two years, colorectal cancer screening, and cholesterol checked within past five years.

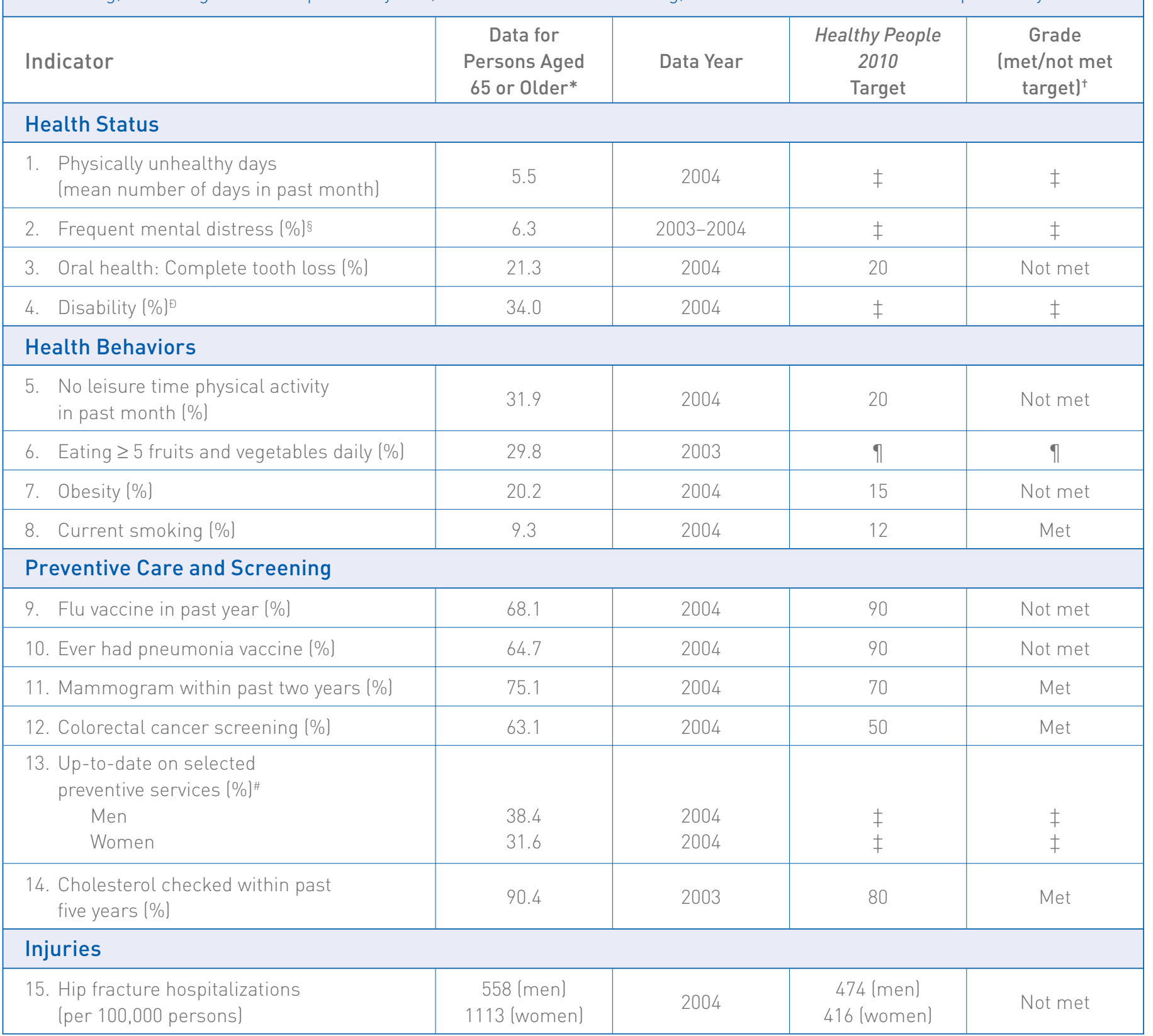

* Data for Indicators 1-14 were collected by CDC's Behavioral Risk Factor Surveillance System (BRFSS), and depict the median for the 50 states and the District of Columbia. Data for Indicator 15, hip fracture hospitalizations, are from CDC's National Center for Health Statistics, National Hospital Discharge Survey. See Appendix for a full description of these data sources.

+ Grade is based on attainment of Healthy People 2010 targets. See Appendix for a full description of Healthy People 2010.

‡ Indicators 1, 2, 4, and 13 are more recently developed measures and do not have Healthy People 2010 targets.

$\S$ Frequent mental distress is defined as having had 14 or more mentally unhealthy days in the previous month. Data from the 2003 and 2004 BRFSS were combined in this report to achieve a sufficient sample size. $\bigoplus$ Disability was defined on the basis of an affirmative response to either of the following two questions on the 2004 BRFSS: "Are you limited in any way in any activities because of physical, mental, or emotional problems?" or "Do you now have any health problem that requires you to use special equipment, such as a cane, a wheelchair, a special bed, or a special telephone?"

I Healthy People 2010 segments the nutrition target into multiple categories of fruits and vegetables. See Appendix for a full description.

\# For men, three services are included: flu vaccine in past year; ever had a pneumonia vaccine; and colorectal cancer screening. For women, these same three services are included, plus a mammogram within past two years. 


\section{Health Status Indicators}

INDICATOR 1:

Physically unhealthy days
- CDC collects data on adults' physically unhealthy days through the Behavioral Risk Factor Surveillance System (BRFSS). Respondents were asked how many of the previous 30 days they felt that their physical health (including physical illness and injury) was not good.

- Older adults suffer the highest rates of poor physical health and activity limitation, according to 2004 BRFSS data.

- Racial and ethnic disparities have been reported through BRFSS in rates of physically unhealthy days. In 2004, among adults aged 65 or older, the average number of physically unhealthy days per month was 4.2 for Asians and Pacific Islanders; 5.5 for non-Hispanic whites; 6.6 for Hispanics; and 6.8 for non-Hispanic blacks. Native Americans and Alaska Natives had the highest level of physically unhealthy days at 7.4 per month.

\section{INDICATOR 2: \\ Frequent mental distress}

- The BRFSS also assesses general mental health status. Respondents were asked to report how many of the previous 30 days their mental health was not good because of stress, depression, or problems with emotions. People who reported 14 or more days of poor mental health were defined as having frequent mental distress (FMD). This definition uses a 14-day minimum period because many health care providers and researchers use a similar duration of mental distress as a marker for clinical depression and anxiety disorders.

- The prevalence of FMD varies among racial and ethnic groups. According to the 2004 BRFSS, among Americans aged 65 or older, the prevalence of FMD was lower among non-Hispanic whites (5.9\%) and Asians and Pacific Islanders (6.1\%) compared with Native Americans and Alaska Natives (8.4\%), non-Hispanic blacks (9.8\%), and Hispanics (11.2\%).

- The percentage of older adults who have lost all their natural teeth has declined substantially since the 1950s (Figure 4). This decline is the result of major improvements in the field of oral health, including community water fluoridation; advanced dental technology; better oral hygiene; and more frequent use of dental services.

- Periodontal (gum) diseases are associated with diabetes and possibly with cardiovascular disease and stroke. These and other oral health problems among older adults can lead to needless pain and suffering; difficulty speaking, chewing, and swallowing; and loss of self-esteem.

FIGURE 4:

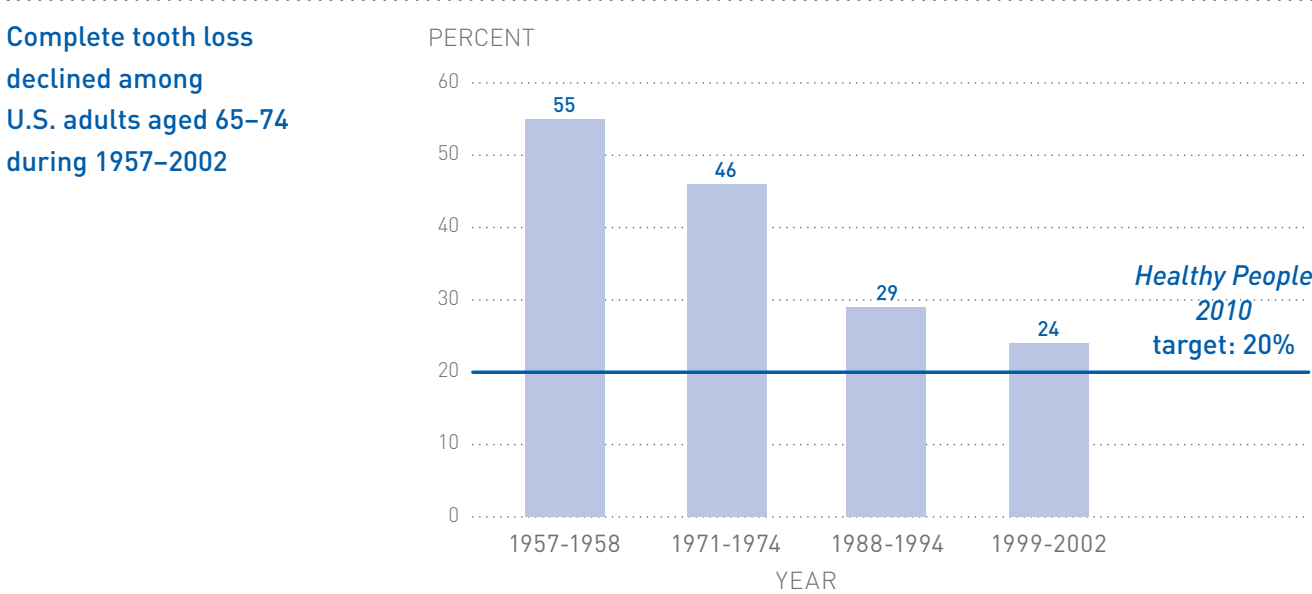

Sources: U.S. Public Health Service, 1960, and CDC, National Center for Health Statistics, National Health and Nutrition Examination Surveys I, III, and 1999-2002, 1975, 1996, and 2005 


\section{»CALL TO ACTION »}

\section{Improving the Oral Health of Older Americans}

Oral health is integral to general health and well-being throughout one's life. The oral health of older adults, however, is often neglected. Many older adults - especially those with low incomes or physical or cognitive limitations - are not able to maintain their oral health or visit a dentist. Medicare does not cover routine dental services; Medicaid coverage is limited and available in fewer than half the states.

Unmet oral health needs among older adults can be addressed only through the coordinated efforts of clinicians, public health professionals, the aging services network, and families. In the past, there has been little collaboration among these groups. CDC's State-Based Examples of Network Innovation, Opportunity, and Replication (SENIOR) grant program includes an oral health component that is designed to identify unmet dental needs among older adults and promote partnerships and community strategies to address these needs.
Other promising approaches to improve the oral health of older adults include:

» State and local efforts to ensure that community drinking water has optimal fluoride content.

» Health communication campaigns to increase public awareness of the importance of oral health and the benefits of fluoride.

» Expanded partnerships among clinical and public health professionals and the aging services network to increase the likelihood that older adults with limited resources and functional abilities receive dental services.

»Development of innovative and effective strategies to prevent and treat dental disease..$^{[1,2,3)}$

For more information on the problem of poor oral health among older Americans, visit http://www. oralhealthamerica.org/OralHealthParity.html.

\section{INDICATOR 4:} Disability
- In this report, disability is defined as an affirmative response to either of the following two BRFSS questions: "Are you limited in any way in any activities because of physical, mental, or emotional problems?" or "Do you now have any health problem that requires you to use special equipment, such as a cane, a wheelchair, a special bed, or a special telephone?"

- According to 2001-2003 BRFSS data, older adults with disabilities are less likely to be physically active and more likely to be obese. However, they are more likely than those without disabilities to have received an influenza or pneumococcal vaccine (Figure 5).

FIGURE 5:

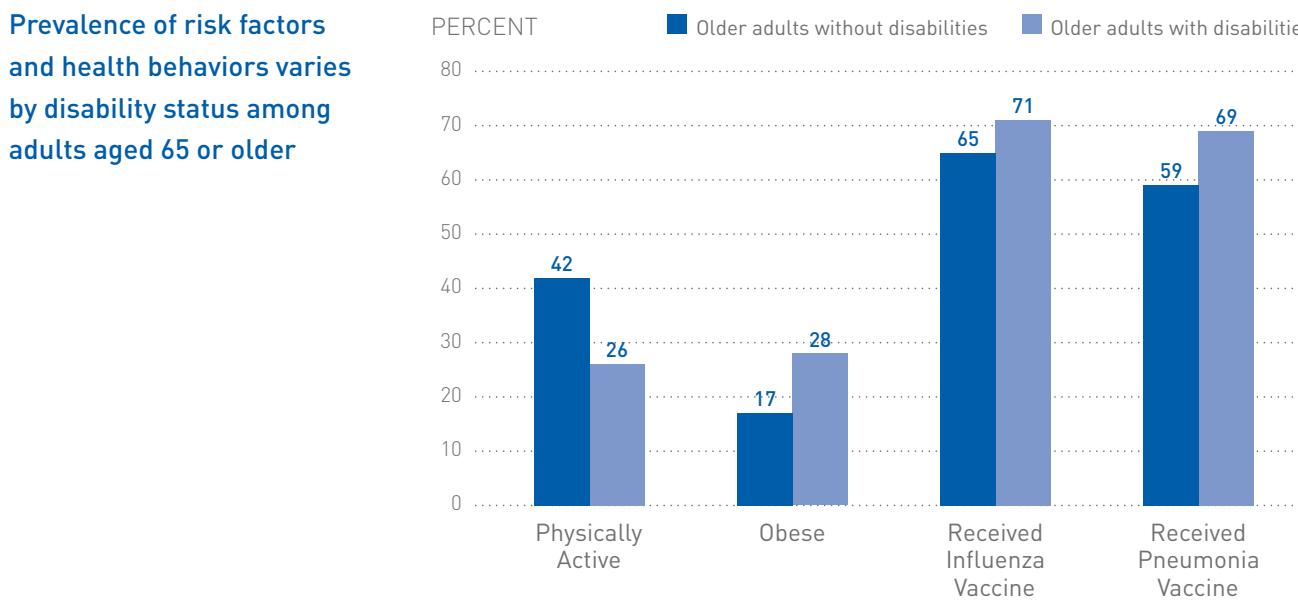




\section{Health Behavior Indicators}

INDICATOR 5:

Physical activity
- Being physically active contributes substantially to healthy aging. Regular physical activity can help prevent or control many of the health problems (e.g., high blood pressure; depression; obesity; and diabetes) that often reduce the quality and length of life for older adults.

- Strength training is of particular importance to older adults, as it can provide relief from arthritis pain; improve balance and reduce the risk of falling; strengthen bones; and reduce blood glucose levels. ${ }^{(4)}$

- Adults in the United States, however, tend to become less active as they age (Figure 6).

FIGURE 6:

Prevalence of no leisure-time physical activity increases as Americans age

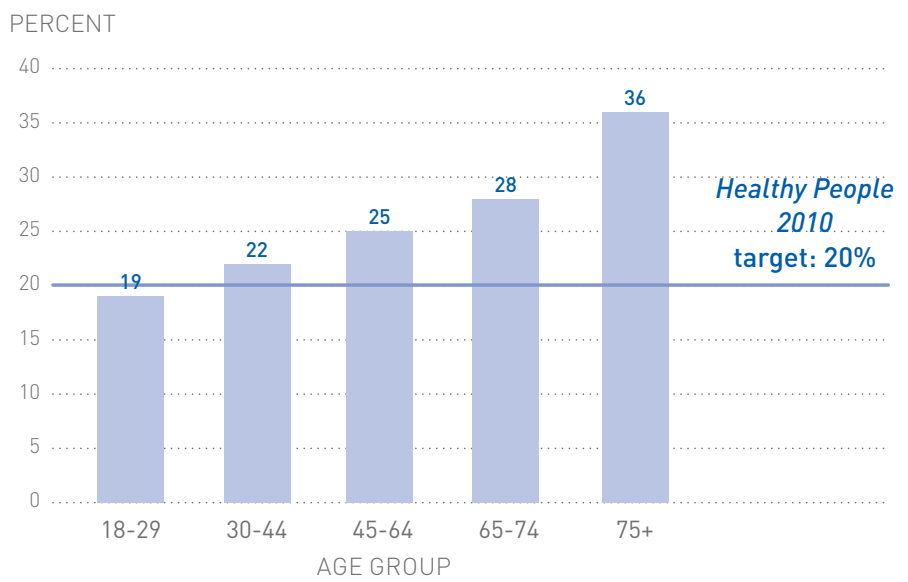

\section{»CALL TO ACTION »}

\section{Encouraging Physical Activity by Promoting Changes to the Physical Environment}

Many older adults are inactive despite efforts to promote the benefits of regular physical activity. Because walking is the most commonly reported form of physical activity among older adults, enhancing community environments to support walking is a promising approach to increase physical activity among seniors. ${ }^{(5)}$

Research shows that modifying a community's physical environment to ensure access to appropriate exercise venues and address barriers to walking may increase the physical activity of older adults. Specific measures include: repairing sidewalks and ensuring sidewalk availability ${ }^{(6)}$; ensuring safety and protection from traffic (for example, by using traffic-calming devices) ${ }^{(7)}$; and protecting older adults from crime. ${ }^{(8)}$ In addition to such environmental enhancements, older adults also may benefit from programs that encourage leisure-time activities. Helping older adults remain active in their own communities is an investment with documented cost saving ${ }^{(9)}$, and making communities safe is beneficial to everyone. 
INDICATOR 6:

Eating five or more

fruits and vegetables daily
- Diets rich in fruits and vegetables may reduce the risk for some cancers and chronic diseases such as diabetes and cardiovascular disease. Fruits and vegetables provide essential vitamins and minerals, fiber, and other substances that are important for good health.

- Compared with other age groups, a greater proportion of adults aged 65 or older eat five or more fruits and vegetables daily.

- BRFSS data from 2003 show that the percentage of older Americans who eat five or more fruits and vegetables varies by race and ethnicity. About $40 \%$ of Asian/Pacific Islander older adults meet the five-a-day recommendation, compared with only $31 \%$ of non-Hispanic whites; $26 \%$ of Hispanics; $25 \%$ of non-Hispanic blacks; and 24\% of Native Americans.
INDICATOR 7:

Obesity
- Obesity is defined as having a body mass index (BMI) of 30 or greater. BMI is calculated by dividing a person's weight in kilograms by his or her height in meters squared $\left(\mathrm{kg} / \mathrm{m}^{2}\right)$.

- Older adults can benefit from maintaining a healthy body weight. Obesity is a risk factor for many chronic conditions, including 4 of the 10 leading causes of death in the United States - coronary heart disease, type 2 diabetes, stroke, and several forms of cancer. Obesity also can worsen conditions such as arthritis, and it is associated with activity limitations and feelings of sadness and hopelessness. ${ }^{(10)}$

\section{INDICATOR 8: Current smoking}

- Although most older adults who were once regular smokers have quit, about $9 \%$ of adults aged 65 or older were still smoking cigarettes in 2004 (see Table 1).

- Postmenopausal women who smoke have lower bone density and an increased risk for hip fracture than women who never smoked. ${ }^{(11)}$

- Even adults who have smoked throughout their lives can gain significant health benefits from quitting. For example, the risk for heart attack declines and overall lung function improves within just two weeks to three months of quitting. ${ }^{(12)}$ 


\section{Preventive Care and Screening Indicators}

INDICATOR 9:

Flu vaccine in past year

INDICATOR 10:

Ever had pneumonia vaccine
- Influenza and pneumonia kill thousands of older adults annually even though both diseases are largely preventable through vaccination. An average of 36,000 people, the majority of whom are aged 65 years or older, die annually from influenza and its complications, and about half of the 5,000 annual deaths from invasive pneumococcal disease occur in this age group. ${ }^{(13)}$

- Major racial and ethnic disparities have been reported for these two indicators (Figure 7). Hispanics and non-Hispanic blacks have the lowest rates of influenza and pneumonia vaccinations.

FIGURE 7:

Rates for flu and pneumonia vaccination varied by race and ethnicity in 2004

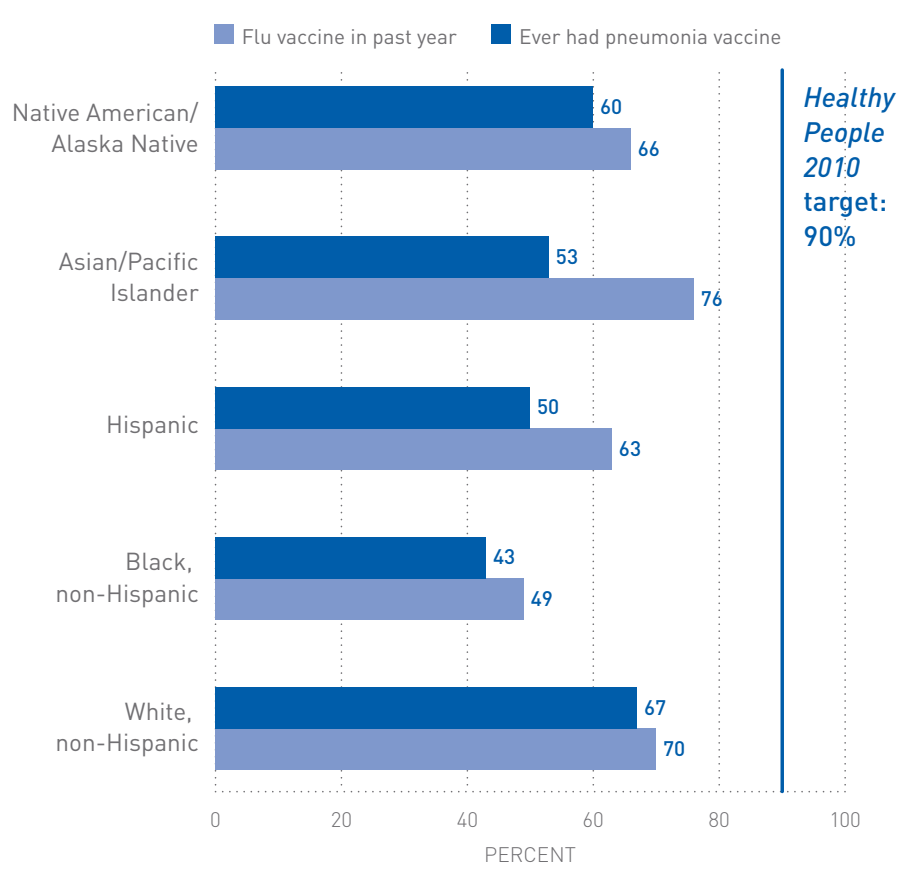




\section{»CALL TO ACTION »}

\section{Increasing Adult Immunization in Racial/Ethnic Minority Populations}

National Healthy People 2010 objectives call for $90 \%$ of noninstitutionalized persons aged 65 years or older to be vaccinated against influenza and pneumonia (see Appendix). Although all population groups currently fall short of this target, AfricanAmericans and Hispanics have significantly lower influenza and pneumococcal immunization rates compared with the rest of the population.

No single factor has been identified that can account for the significant racial/ethnic disparities in vaccination of older persons. Recent research provides evidence for multiple factors that may contribute to this problem, including lower education levels, lower likelihood of vaccination in non-medical settings among African Americans, less awareness about current vaccine recommendations, and possibly more missed opportunities for vaccination by providers. ${ }^{(14)}$ Although the differences caused by any of these individual factors may be slight, in combination these could lead to the larger disparities observed in vaccination rates among racial/ethnic groups. Focus group research suggests that the desire to protect family members, particularly grandchildren, may be an important motivator for these groups. ${ }^{(15)}$

The READII (Racial and Ethnic Adult Disparities in Immunization Initiative) project has been a significant effort to address these disparities through multi-year demonstration projects. Conducted in five areas (Monroe County, NY; Milwaukee, WI; San Antonio, TX; Chicago, IL; and 18 counties in the Mississippi Delta Region and Hinds County, MS) from August 2002 through December 2004, these projects aimed to improve influenza and pneumococcal vaccination levels among elderly non-Hispanic blacks and/or Hispanics. Each site identified community partners and, together, identified a plan for increasing vaccination rates in their target population(s) based on evidence-based interventions recommended in the Guide to Community Preventive Services. Examples of specific activities conducted included working with pharmacists to offer vaccinations, collaborating with the faith-based community, conducting assessment and feedback activities in physician offices, and implementing a tracking/ recall/outreach system in clinics serving the target population.

Systematic offering of vaccine to all patients, as was conducted in Monroe County, NY, was shown to reduce disparities in participating practices. Another key outcome was the development of new partnerships that facilitated reaching the target populations, and have continued after the end of the demonstration period.

More information on this program may be found at http://www.cdc.gov/nip/specint/readii.

\section{INDICATOR 11: Mammogram within past two years}

- The risk of getting breast cancer increases as a woman gets older. Nearly 8 of 10 cases of breast cancer are found in women over age $50 .{ }^{(16)}$

- Early detection of breast cancer saves lives, and mammography is the best available method to detect breast cancer in its earliest, most treatable stage, several years before a lump can be felt. Timely mammography screening among women aged 40 or older could reduce breast cancer mortality by approximately $16 \%$ compared with women who are not screened. ${ }^{(17)}$

- Mammograms for women aged 65 or older are covered by Medicare, but many women are still not taking advantage of this opportunity. 


\section{Preventive Care and Screening Indicators}

\section{INDICATOR 12: Colorectal cancer screening}

- Colorectal cancer is the third most common type of cancer for both men and women and the second leading cause of cancer death in the United States. ${ }^{(18)}$ More than $90 \%$ of cases are diagnosed in people aged 50 or older. In 2002, a total of 70,651 men and 68,883 women received a diagnosis of colorectal cancer, and 28,471 men and 28,132 women died from this disease. ${ }^{(19)}$

- The Healthy People 2010 target for colorectal cancer screening is to increase the proportion of people aged 50 or older who have ever received a sigmoidoscopy to 50\%. However, the data included in this report are graded against the current screening recommendations from the U.S. Preventive Services Task Force, which are more comprehensive. The Task Force recommends the following screening tests and intervals for adults aged 50 or older who are at average risk for colorectal cancer: ${ }^{(20)}$

- A fecal occult blood test (FOBT) every year

- Flexible sigmoidoscopy every 5 years

- Double-contrast barium enema every 5 years

- Colonoscopy every 10 years.

\section{»CALL TO ACTION »}

\section{Increasing Screening for Colorectal Cancer}

Colorectal cancer (CRC), one of the most commonly diagnosed cancers in the United States, is largely preventable. Although it is the second leading cancer killer, as many as $60 \%$ of deaths from CRC could be prevented if everyone aged 50 or older were screened regularly. Screening tests can detect precancerous polyps so they can be removed before they become malignant. Screening also can be effective in finding early-stage CRC. ${ }^{(21)}$

Despite recent increases in screening rates, much work is needed to achieve the Healthy People 2010 target for reducing $\mathrm{CRC}$ mortality. To further increase screening rates, barriers to screening must be addressed. These barriers include high costs, lack of insurance coverage, failure of many clinicians to recommend screening, and lack of awareness among populations at higher risk. Continuing efforts are needed to raise awareness, increase physician recommendations, and ensure that screening and follow-up care are available for underinsured and uninsured patients.
$\mathrm{CDC}$ is working to raise awareness about the importance of CRC screening through its Screen for Life: National Colorectal Cancer Action Campaign. This campaign is a collaborative effort of CDC and the Entertainment Industry Foundation; National Colorectal Cancer Research Alliance; 49 state health departments; two tribal organizations; and the District of Columbia, all of which are using or adapting campaign materials for their community education efforts. The campaign develops and disseminates multimedia public service announcements and educational materials for patients and health care providers in both English and Spanish. Target audiences include the general population aged 50 or older and health professionals.

For more information, visit http://www.cdc.gov/screenforlife. 
INDICATOR 13:

Up-to-date on selected preventive services
- The "up-to-date" indicator presents a composite picture of the preventive care and screening behaviors of older adults. Indicators 9-12 measure the use of selected clinical preventive services that are covered by Medicare and recommended for adults aged 65 or older. Although each indicator is essential independently, older adults need to obtain all of these services to protect their health.

- This comprehensive approach aims to provide a more meaningful and practical measure of the delivery of clinical preventive services. This approach also could enhance the ability of health departments and community groups to assess disparities in the delivery of preventive services; to better gauge progress toward measurable objectives; and to identify best practices for achieving prevention goals. ${ }^{(22)}$
INDICATOR 14:

Cholesterol screening
- High serum cholesterol is a major risk factor for coronary heart disease, a leading cause of illness and death among older adults. Periodic cholesterol screening is an essential component of preventive health care. Fasting cholesterol levels should be measured every five years for all adults. ${ }^{(23)}$

- Among the major U.S. racial and ethnic groups, Hispanics were the least likely and non-Hispanic blacks the most likely to have had their cholesterol measured within the past five years in 2003. ${ }^{(24)}$

- Cholesterol screening within the past five years rose with education levels among older adults in 2003 (Figure 8).

FIGURE 8:

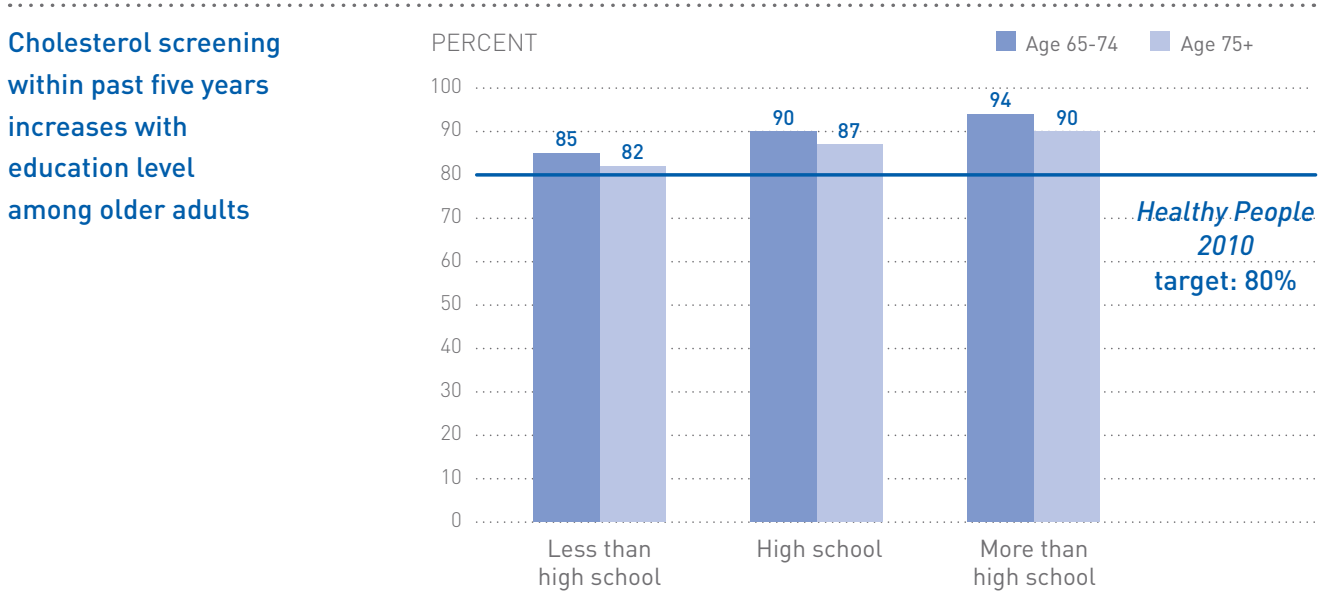

EDUCATION LEVEL 


\section{Injury Indicator}

\section{INDICATOR 15: \\ Hip fracture \\ hospitalizations}

- Hip fracture, the most serious type of all fall-related fractures, is a major contributor to death, disability, and diminished quality of life among older adults. ${ }^{(25,26)}$

- In 2004, women had nearly double the rate of hospitalizations for hip fractures than men (1,113 per 100,000 persons compared with 558).

- Hip fracture hospitalizations have varied from year to year, but are always consistently above the Healthy People 2010 targets of 474 per 100,000 persons for men and 416 per 100,000 persons for women.

\section{Selected Additional Resources}

The following resources provide more information on the indicators described in this chapter. See the chapter titled Spotlight: Reducing Falls Among Older Adults for resources related to fall prevention and hip fractures.

\section{Physically Unhealthy Days and Frequent Mental Distress}

- CDC, Health-Related Quality of Life Program http://www.cdc.gov/hrqol

\section{Oral Health}

- CDC, Oral Health Program http://www.cdc.gov/OralHealth/index.htm

- Oral Health America http://www.oralhealthamerica.org

\section{Disability}

- Administration on Aging, Aging and Disability Resource Centers http://www.aoa.gov/prof/aging_dis/aging_dis.asp

- CDC, Disability Program http://www.cdc.gov/ncbddd/dh/default.htm

\section{Nutrition and Obesity}

- CDC, Nutrition Program http://www.cdc.gov/nccdphp/dnpa/nutrition.htm

- CDC, Obesity Program http://www.cdc.gov/nccdphp/dnpa/obesity/index.htm

- 5-a-Day Program http://www.5aday.gov

\section{Physical Activity}

- CDC, Physical Activity Program http://www.cdc.gov/nccdphp/dnpa/physical/index.htm

- CDC, Growing Stronger Program http://www.cdc.gov/nccdphp/dnpa/physical/growing_stronger/index.htm

- National Blueprint: Increasing Physical Activity Among Adults Aged 50 and Older http://www.agingblueprint.org

\section{Tobacco}

- American Lung Association http://www.lungusa.org

- CDC, Tobacco Control Program http://www.cdc.gov/tobacco

\section{Immunizations}

- CDC, Immunization Program http://www.cdc.gov/nip

\section{Cancer Screening}

- American Cancer Society http://www.cancer.org

- CDC, Cancer Control Program http://www.cdc.gov/cancer

Cholesterol Screening

- CDC, Cholesterol Fact Sheet http://www.cdc.gov/DHDSP/library/fs_cholesterol.htm 


\section{References}

1. Centers for Disease Control and Prevention. Surveillance for dental caries, dental sealants, tooth retention, edentulism, and enamel fluorosis-United States, 1988-1993 and 1999-2002. MMWR Surveillance Summaries 2005;54(No. SS-3):1-33.

2. Griffin SO, Griffin PM, Swann JL, Zlobin N. New coronal caries in older adults: implications for prevention. Journal of Dental Research 2005;84(8):715-720.

3. Griffin SO, Griffin PM, Swann, JL, Zlobin N. Estimating rates of new root caries in older adults. Journal of Dental Research 2004;83(8):634-638.

4. Centers for Disease Control and Prevention. Growing stronger: why strength training for older adults? Available at http://www.cdc. gov/nccdphp/dnpa/physical/growing_stronger/why.htm laccessed May 23, 2006).

5. Hoehner CM, Brennan Ramirez LK, Elliott MB, Handy SL, Brownson RC. Perceived and objective environmental measures and physical activity among urban adults. American Journal of Preventive Medicine 2005;28:105-116.

6. Wilcox S, Castro C, King AC, Houseman R, Brownson RC. Determinants of leisure-time physical activity in rural older and ethnically diverse women in the United States. Journal of Epidemiology and Community Health 2000;54:667-672.

7. Kitamura R, Patricia L, Laidit L. A micro-analysis of land use and travel in five neighborhoods in the San Francisco Bay Area. Transportation 1997;24:125-158.

8. Centers for Disease Control and Prevention. Neighborhood safety and the prevalence of physical inactivity - selected states, 1996. Morbidity and Mortality Weekly Report 1999;48(7):143-146.

9. Pratt M, Macera CA, Wang G. Higher direct medical costs associated with physical inactivity. The Physician and Sportsmedicine 2000;28(10):63-70.

10. Center on an Aging Society. Obesity among older Americans (Data Profile). Washington, DC: Georgetown University; 2003. Available at http://ihcrp.georgetown.edu/agingsociety/pubhtml/obesity2/ obesity2.html laccessed April 24, 2006).

11. U.S. Department of Health and Human Services. Women and smoking: a report of the Surgeon General. Rockville, MD: U.S. Department of Health and Human Services, Centers for Disease Control and Prevention; 2001. Available at http://www.cdc.gov/ tobacco/sgr/sgr_forwomen/index.htm (accessed May 23, 2006).

12. Centers for Disease Control and Prevention. Within 20 minutes of quitting (Poster). Available at http://www.cdc.gov/tobacco/sgr/sgr 2004/posters/20mins.htm laccessed May 23, 2006).

13. Centers for Disease Control and Prevention. Racial and Ethnic Adult Disparities in Immunization Initiative (READII) Web site. Available at http://www.cdc.gov/nip/specint/readii laccessed May 23, 2006).
14. Singleton J, Santibanez T, Wortley PM. Influenza and pneumococcal vaccination of adults $\geq 65$ : racial/ethnic differences. Am J Prev Med $2005 ; 29: 412-20$.

15. Centers for Disease Control and Prevention. Influenza and pneumococcal immunization: a qualitative assessment of the beliefs of physicians and older Hispanic and African Americans. Atlanta, GA: U.S. Department of Health and Human Services, Centers for Disease Control and Prevention; 2002.

16. American Cancer Society. What causes breast cancer? Available at http://www.cancer.org/docroot/CRI/content/CRI_2_2_2X_What_ causes_breast_cancer_5.asp?sitearea= (accessed May 23, 2006).

17. Centers for Disease Control and Prevention. The National Breast and Cervical Cancer Early Detection Program: saving lives through screening. Atlanta, GA: U.S. Department of Health and Human Services, Centers for Disease Control and Prevention; 2006. Available at http://www.cdc.gov/cancer/nbccedp/about2004.htm (accessed April 24, 2006).

18. American Cancer Society. What are the key statistics for colorectal cancer? Available at http://www.cancer.org/docroot/CRI/content/ CRI_2_4_1X_What_are_the_key_statistics_for_colon_and_rectum_ cancer.asp?rnav=cri (accessed May 23, 2006).

19. U.S. Cancer Statistics Working Group. U.S. cancer statistics: 2002 incidence and mortality. National Vital Statistics Report 2004;53(5).

20. Centers for Disease Control and Prevention. Colorectal cancer test use among persons aged $>50$ years - United States, 2001. Morbidity and Mortality Weekly Report 2003;52(1);193-196.

21. Seeff LC, King J, Pollack LA, Williams KN. Increased use of colorectal cancer tests - United States, 2002 and 2004. Morbidity and Mortality Weekly Report 2006;55(11);308-311.

22. Shenson D, Bolen J, Adams M, Seeff L, Blackman D. Are older adults up-to-date with cancer screening and vaccinations? Prevention of Chronic Diseases [serial online]; July 2005. Available at http://www. cdc.gov/pcd/issues/2005/jul/05_0021.htm laccessed May 23, 2006).

23. National Institutes of Health. Third Report of the National Cholesterol Education Program (NCEP) Expert Panel on Detection, Evaluation, and Treatment of High Blood Cholesterol in Adults (Adult Treatment Panel III) Executive Summary. 2001. Available at http://www.nhlbi.nih.gov/ guidelines/cholesterol/atp3xsum.pdf (accessed May 23, 2006).

24. Centers for Disease Control and Prevention. Trends in cholesterol screening and awareness of high blood cholesterol - United States, 1991-2003. Morbidity and Mortality Weekly Report 2005;54(35):865 -870.

25. Wolinksy FD, Fitzgerald JF, Stump TE. The effect of hip fracture on mortality, hospitalization, and functional status: a prospective study. American Journal of Public Health 1997;87(3):498-503.

26. Hall SE, Williams JA, Goldswain, PR, Criddle RA. Hip fracture outcomes: quality of life and functional status in older adults living in the community. Australian and New Zealand Journal of Medicine 2000;30(3):327-332. 

TABLE 2

\section{State-by-State Report Card On Healthy Aging}

\section{Summary of Findings:}

There is considerable variation among the states for each indicator, and mixed progress has been made since The State of Aging and Health in America 2004 was released. For example,

- No states have met all the targets.

- Hawaii was most often ranked in the top five (eight times). Kentucky was most often ranked in the bottom five (nine times).

- All states already meet the Healthy People 2010 target for cholesterol screening.

- The vast majority of states are well ahead of schedule for meeting Healthy People 2010 targets for mammograms, colorectal cancer screenings, and people currently smoking.

- No states met the 2010 targets for physical activity, flu or pneumonia vaccines and eating fruit and vegetables daily. Only three states met the 2010 target on obesity, while 21 states and the District of Columbia met the target on oral health.

- Variation among states can be significant. For example, in Connecticut, only $12.4 \%$ of older adults had lost all of their teeth; while West Virginia ranked last in this category, with $42.9 \%$ of older adults experiencing complete tooth loss.

\begin{tabular}{|c|c|c|c|c|c|}
\hline Indicator & Data Year* & $\begin{array}{c}\text { Healthy } \\
\text { People } 2010 \\
\text { Target }\end{array}$ & $\begin{array}{l}\text { Number } \\
\text { of States } \\
\text { Meeting } \\
\text { Target }^{+}\end{array}$ & $\begin{array}{l}\text { Worst-Ranked } \\
\text { State } \\
\text { (relevant data) }\end{array}$ & $\begin{array}{l}\text { Best-Ranked } \\
\text { State } \\
\text { (relevant data) }\end{array}$ \\
\hline \multicolumn{6}{|l|}{ Health Status } \\
\hline $\begin{array}{l}\text { 1. Physically unhealthy days } \\
\text { (mean number of days in past month) }\end{array}$ & 2004 & $\ddagger$ & $\ddagger$ & West Virginia (7.9) & Hawaii (3.2) \\
\hline 3. Oral health: complete tooth loss (\%) & 2004 & 20 & 22 & West Virginia (42.9) & Connecticut (12.4) \\
\hline 4. Disability $(\%)^{\oplus}$ & 2004 & $\ddagger$ & $\ddagger$ & West Virginia (42.3) & Hawaii (20.6) \\
\hline \multicolumn{6}{|l|}{ Health Behaviors } \\
\hline $\begin{array}{l}\text { 5. No leisure-time physical activity } \\
\text { in past month (\%) }\end{array}$ & 2004 & 20 & 0 & Mississippi (43.4) & Minnesota (23.1) \\
\hline 8. Current smoking $(\%)$ & 2004 & 12 & 47 & Nevada (14.5) & Utah (4.7) \\
\hline \multicolumn{6}{|l|}{ Preventive Care and Screening } \\
\hline 9. Flu vaccine in past year $(\%)$ & 2004 & 90 & 0 & DC (54.9) & Colorado (78.8) \\
\hline 10. Ever had pneumonia vaccine $(\%)$ & 2004 & 90 & 0 & DC (51.4) & Montana (71.6) \\
\hline 11. Mammogram within past two years (\%) & 2004 & 70 & 47 & Mississippi (66.3) & Rhode Island (84.8) \\
\hline 12. Colorectal cancer screening (\%) & 2004 & 50 & 50 & Hawaii (35.9) & Maine (73.4) \\
\hline $\begin{array}{l}\text { 13. Up-to-date on selected } \\
\text { preventive services }(\%)^{\#} \\
\text { Men } \\
\text { Women }\end{array}$ & $\begin{array}{l}2004 \\
2004\end{array}$ & $\begin{array}{l}\ddagger \\
\ddagger\end{array}$ & $\begin{array}{l}\ddagger \\
\ddagger\end{array}$ & $\begin{array}{l}\text { Hawaii (20.1) } \\
\text { Mississippi (24.7) }\end{array}$ & $\begin{array}{l}\text { Wisconsin (49.8) } \\
\text { Minnesota (47.0) }\end{array}$ \\
\hline
\end{tabular}

* Data for Indicators 1-14 were collected by CDC's Behavioral Risk Factor Surveillance System (BRFSS). See Appendix for a full description of this data source.

+ Includes all 50 states and the District of Columbia.

I Indicators 1, 2, 4, and 13 are more recently developed measures and do not have Healthy People 2010 targets.

$\S$ Frequent mental distress is defined as having had 14 or more mentally unhealthy days in the previous month. Data from the 2003 and 2004 BRFSS are combined in this report to achieve a sufficient sample size.

$\bigoplus$ Disability was defined on the basis of an affirmative response to either of the following two questions on the 2004 BRFSS: "Are you limited in any way in any activities because of physical, mental, or emotional problems?" or "Do you now have any health problem that requires you to use special equipment, such as a cane, a wheelchair, a special bed, or a special telephone?"

I Healthy People 2010 segments the nutrition target into multiple categories of fruits and vegetables. See Appendix for a full description.

\# For men, three services are included: influenza vaccine in past year; ever had a pneumonia vaccine; and colorectal cancer screening. For women, these same three services are included, plus a mammogram within past two years.

** No state-level data exist for Indicator 15, hip fracture hospitalizations. 
TABLE 3

State-by-State Report Card On Healthy Aging*

\begin{tabular}{|c|c|c|c|c|c|c|c|c|c|c|c|c|c|c|c|}
\hline & \multicolumn{3}{|c|}{$\begin{array}{l}\text { Physically Unhealthy } \\
\text { Days (mean number } \\
\text { of days in past month) } \\
2004\end{array}$} & \multicolumn{3}{|c|}{$\begin{array}{c}\text { Frequent } \\
\text { Mental Distress }^{+} \\
{[\%]} \\
2003-2004\end{array}$} & \multicolumn{3}{|c|}{$\begin{array}{c}\text { Oral Health: } \\
\text { Complete Tooth Loss } \\
{[\%]} \\
2004\end{array}$} & \multicolumn{3}{|c|}{$\begin{array}{c}\text { Disability }^{+} \\
{[\%]} \\
2004\end{array}$} & \multicolumn{3}{|c|}{$\begin{array}{c}\text { No Leisure-Time } \\
\text { Physical Activity } \\
{[\%]} \\
2004\end{array}$} \\
\hline & Data & Rank ${ }^{\ddagger}$ & Grade & Data & Rank & Grade & Data & Rank & Grade & Data & Rank & Grade & Data & Rank & Grade \\
\hline Alabama & 7.3 & 49 & 0 & 9.6 & 50 & 0 & 31.9 & 47 & $\theta$ & 35.9 & 36 & 0 & 39.7 & 48 & 0 \\
\hline Alaska & 5.0 & 8 & 0 & 8.1 & 47 & 0 & 23.0 & 31 & $\ominus$ & 35.7 & 35 & 0 & 34.9 & 39 & $\odot$ \\
\hline Arizona & 5.0 & 8 & $\bullet$ & 6.3 & 24 & e & 15.0 & 5 & - & 30.5 & 7 & 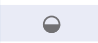 & 27.8 & 9 & - \\
\hline Arkansas & 6.0 & 39 & $\odot$ & 6.4 & 27 & $\bullet$ & 24.7 & 36 & $\ominus$ & 34.4 & 28 & $\ominus$ & 34.4 & 37 & $\ominus$ \\
\hline California & 5.4 & 16 & $\bullet$ & 8.5 & 48 & 0 & 13.8 & 3 & - & 32.4 & 21 & $\odot$ & 25.5 & 3 & - \\
\hline Colorado & 5.4 & 16 & $\bullet$ & 5.3 & 8 & - & 18.1 & 15 & - & 32.5 & 22 & 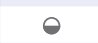 & 29.1 & 15 & - \\
\hline Connecticut & 5.5 & 24 & $\bullet$ & 5.7 & 15 & - & 12.4 & 1 & - & 29.4 & 3 & 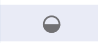 & 28.3 & 11 & - \\
\hline Delaware & 4.9 & 6 & $\bullet$ & 6.2 & 20 & $\ominus$ & 21.2 & 25 & - & 31.6 & 14 & $\ominus$ & 28.6 & 13 & - \\
\hline District of Columbia & 4.6 & 2 & - & 8.0 & 46 & $\odot$ & 19.4 & 19 & - & 29.8 & 5 & $\bullet$ & 36.9 & 43 & 0 \\
\hline Florida & 5.4 & 16 & $\ominus$ & 7.0 & 36 & $\odot$ & 18.7 & 17 & - & 31.7 & 18 & $\ominus$ & 27.5 & 8 & - \\
\hline Georgia & 6.8 & 47 & 0 & 6.3 & 24 & $\ominus$ & 28.3 & 42 & $\bullet$ & 41.2 & 50 & 0 & 40.0 & 49 & 0 \\
\hline Hawaii $c$ & 3.2 & 1 & - & 3.8 & 1 & - & & NO DATA & & 20.6 & 1 & - & 26.0 & 4 & - \\
\hline Idaho & 5.6 & 29 & $\bullet$ & 6.2 & 20 & $\bullet$ & 22.5 & 30 & $\bullet$ & 36.0 & 37 & 0 & 29.4 & 16 & - \\
\hline Illinois & 6.1 & 41 & 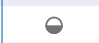 & 5.3 & 8 & - & 18.8 & 18 & - & 32.5 & 22 & 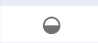 & 35.0 & 40 & ○ \\
\hline Indiana & 5.8 & 34 & $\circ$ & 5.7 & 15 & - & 27.3 & 40 & $\ominus$ & 31.5 & 13 & $\ominus$ & 37.2 & 45 & 0 \\
\hline lowa & 4.8 & 3 & $\bullet$ & 4.2 & 2 & - & 23.3 & 33 & 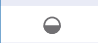 & 30.7 & 8 & ○ & 31.9 & 26 & 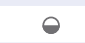 \\
\hline Kansas & 4.8 & 3 & $\ominus$ & 5.0 & 6 & - & 27.8 & 41 & $\bullet$ & 36.2 & 38 & 0 & 33.9 & 35 & $\bullet$ \\
\hline Kentucky & 6.6 & 45 & 0 & 10.3 & 51 & 0 & 38.1 & 49 & 0 & 38.5 & 42 & 0 & 36.2 & 42 & $\ominus$ \\
\hline Louisiana & 5.4 & 16 & $\bullet$ & 7.2 & 41 & $\ominus$ & 31.4 & 46 & $\ominus$ & 31.6 & 14 & $\ominus$ & 40.9 & 50 & 0 \\
\hline Maine & 5.2 & 12 & $\bullet$ & 6.4 & 27 & $\ominus$ & 24.3 & 35 & $\ominus$ & 30.3 & 6 & $\odot$ & 32.5 & 30 & $\odot$ \\
\hline Maryland & 5.0 & 8 & $\odot$ & 7.7 & 45 & $\odot$ & 16.7 & 9 & - & 31.8 & 20 & $\ominus$ & 31.7 & 24 & $\odot$ \\
\hline Massachusetts & 4.9 & 6 & 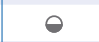 & 6.2 & 20 & $\odot$ & 16.5 & 7 & - & 31.2 & 10 & $\odot$ & 27.9 & 10 & - \\
\hline Michigan & 5.9 & 36 & $\ominus$ & 5.8 & 17 & - & 17.2 & 13 & - & 36.5 & 41 & 0 & 31.6 & 23 & $\ominus$ \\
\hline Minnesota & 5.2 & 12 & $\bullet$ & 4.2 & 2 & - & 14.3 & 4 & - & 38.5 & 42 & 0 & 23.1 & 1 & - \\
\hline Mississippi & 7.3 & 49 & 0 & 7.0 & 36 & 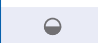 & 29.6 & 44 & 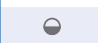 & 39.5 & 45 & 0 & 43.4 & 51 & 0 \\
\hline Missouri & 6.5 & 44 & 0 & 6.8 & 31 & $\bullet$ & 25.2 & 38 & $\ominus$ & 38.8 & 44 & 0 & 33.1 & 33 & $\bullet$ \\
\hline Montana & 5.8 & 34 & $\ominus$ & 5.6 & 14 & - & 19.6 & 21 & - & 31.6 & 14 & 0 & 29.4 & 16 & - \\
\hline Nebraska & 5.3 & 14 & $\odot$ & 5.2 & 7 & - & 23.1 & 32 & $\ominus$ & 34.8 & 32 & $\circ$ & 26.9 & 7 & - \\
\hline Nevada & 5.6 & 29 & $\odot$ & 7.2 & 41 & $\ominus$ & 16.5 & 7 & - & 31.3 & 11 & $\ominus$ & 30.8 & 22 & $\odot$ \\
\hline New Hampshire & 5.7 & 31 & $\bullet$ & 5.8 & 17 & - & 21.1 & 24 & - & 32.5 & 22 & $\ominus$ & 31.7 & 24 & $\ominus$ \\
\hline New Jersey & 5.4 & 16 & $\odot$ & 7.1 & 38 & $\bullet$ & 17.0 & 12 & - & 29.6 & 4 & $\ominus$ & 32.6 & 31 & $\bullet$ \\
\hline New Mexico & 7.2 & 48 & 0 & 6.5 & 29 & $\ominus$ & 21.8 & 27 & - & 36.3 & 40 & 0 & 28.4 & 12 & - \\
\hline New York & 5.4 & 16 & $\ominus$ & 6.7 & 30 & $\ominus$ & 16.9 & 11 & - & 34.6 & 30 & $\ominus$ & 35.6 & 41 & $\bullet$ \\
\hline North Carolina & 6.3 & 42 & 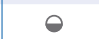 & 7.2 & 41 & 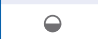 & 28.3 & 42 & 0 & 33.8 & 25 & 0 & 30.4 & 19 & 0 \\
\hline North Dakota & 5.4 & 16 & $\odot$ & 5.4 & 11 & - & 25.0 & 37 & $\ominus$ & 34.0 & 26 & $\ominus$ & 37.2 & 45 & 0 \\
\hline Ohio & 5.5 & 24 & 0 & 7.1 & 38 & 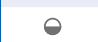 & 20.4 & 23 & - & 31.4 & 12 & 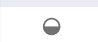 & 32.7 & 32 & $\ominus$ \\
\hline Oklahoma & 6.0 & 39 & $\bullet$ & 7.3 & 44 & $\ominus$ & 31.2 & 45 & $\ominus$ & 39.6 & 46 & 0 & 34.6 & 38 & $\ominus$ \\
\hline Oregon & 5.4 & 16 & $\bullet$ & 6.3 & 24 & $\ominus$ & 17.8 & 14 & - & 40.2 & 49 & 0 & 24.2 & 2 & - \\
\hline Pennsylvania & 5.5 & 24 & $\bullet$ & 4.9 & 5 & - & 23.8 & 34 & $\ominus$ & 31.7 & 18 & $\bullet$ & 37.0 & 44 & 0 \\
\hline Rhode Island & 5.5 & 24 & $\circ$ & 6.8 & 31 & 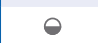 & 18.4 & 16 & - & 28.4 & 2 & $\ominus$ & 34.3 & 36 & $\ominus$ \\
\hline South Carolina & 6.6 & 45 & 0 & 7.1 & 38 & $\ominus$ & 21.8 & 27 & - & 34.5 & 29 & $\ominus$ & 33.3 & 34 & $\bullet$ \\
\hline South Dakota & 4.8 & 3 & $\odot$ & 5.3 & 8 & - & 26.1 & 39 & $\ominus$ & 34.7 & 31 & $\ominus$ & 28.8 & 14 & - \\
\hline Tennessee & 5.9 & 36 & $\bullet$ & 6.8 & 31 & $\bullet$ & 32.3 & 48 & $\ominus$ & 31.6 & 14 & e & 38.4 & 47 & 0 \\
\hline Texas & 6.3 & 42 & $\odot$ & 6.9 & 35 & $\odot$ & 16.8 & 10 & - & 36.2 & 38 & 0 & 30.5 & 20 & $\ominus$ \\
\hline Utah & 5.7 & 31 & 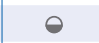 & 6.2 & 20 & 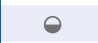 & 13.6 & 2 & - & 39.9 & 47 & 0 & 26.5 & 6 & - \\
\hline Vermont & 5.1 & 11 & $\odot$ & 4.8 & 4 & - & 21.3 & 26 & - & 35.4 & 33 & 0 & 32.2 & 29 & $\odot$ \\
\hline Virginia & 5.7 & 31 & $\bullet$ & 5.4 & 11 & - & 19.4 & 19 & - & 31.0 & 9 & 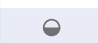 & 32.1 & 27 & $\odot$ \\
\hline Washington & 5.5 & 24 & $\odot$ & 5.8 & 17 & - & 16.1 & 6 & - & 40.1 & 48 & o & 26.0 & 4 & - \\
\hline West Virginia & 7.9 & 51 & 0 & 9.1 & 49 & 0 & 42.9 & 50 & 0 & 42.3 & 51 & 0 & 32.1 & 27 & $\odot$ \\
\hline Wisconsin & 5.3 & 14 & $\ominus$ & 6.8 & 31 & $\odot$ & 19.7 & 22 & - & 34.1 & 27 & $\ominus$ & 29.9 & 18 & $\ominus$ \\
\hline Wyoming & 5.9 & 36 & 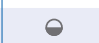 & 5.5 & 13 & - & 21.8 & 27 & $\bullet$ & 35.6 & 34 & 0 & 30.6 & 21 & $\ominus$ \\
\hline
\end{tabular}

* Grades are calculated as tertiles (thirds) and show state performance relative to all other states; $=$ upper third (top performing 33\%), $\bullet=$ middle third (middle $33 \%), \mathrm{O}=$ lower third (lowest performing 33\%). online version of this report at www.cdc.gov/aging. Defined in Table 2

‡Rankings are based on the relative numeric scores for each indicator, with a ranking of " 1 " indicating the highest rank. When comparing states, we 


\begin{tabular}{|c|c|c|c|c|c|c|c|c|c|c|c|c|c|c|c|}
\hline & \multicolumn{3}{|c|}{$\begin{array}{c}\text { Eating } \geq 5 \text { Fruits } \\
\text { and Vegetables Daily } \\
(\%) \\
2003\end{array}$} & \multicolumn{3}{|c|}{$\begin{array}{l}\text { Obesity }^{+} \\
\text {(\%) } \\
2004\end{array}$} & \multicolumn{3}{|c|}{$\begin{array}{l}\text { Current Smoking } \\
\qquad[\%] \\
2004\end{array}$} & \multicolumn{3}{|c|}{$\begin{array}{c}\text { Flu Vaccine } \\
\text { in Past Year } \\
{[\%]} \\
2004\end{array}$} & \multicolumn{3}{|c|}{$\begin{array}{c}\text { Ever Had Pneumonia } \\
\text { Vaccine } \\
{[\%]} \\
2004\end{array}$} \\
\hline & Data & Rank & Grade & Data & Rank & Grade & Data & Rank & Grade & Data & Rank & Grade & Data & Rank & Grade \\
\hline Alabama & 28.9 & 34 & $\ominus$ & 24.5 & 50 & 0 & 12.1 & 47 & 0 & 66.2 & 37 & 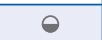 & 60.1 & 44 & $\ominus$ \\
\hline Alaska & 23.7 & 44 & 0 & 23.4 & 46 & 0 & 12.5 & 48 & 0 & 64.1 & 48 & ○ & 57.2 & 50 & 0 \\
\hline Arizona & 27.7 & 38 & $\bullet$ & 17.8 & 10 & 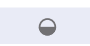 & 7.9 & 11 & $\bullet$ & 66.2 & 37 & 0 & 68.6 & 10 & - \\
\hline Arkansas & 29.3 & 32 & $\bullet$ & 19.1 & 18 & $\ominus$ & 9.3 & 26 & $\theta$ & 68.7 & 23 & 0 & 62.0 & 40 & $\theta$ \\
\hline California & 36.2 & 6 & $\bullet$ & 18.6 & 14 & 0 & 6.3 & 2 & - & 70.9 & 18 & - & 63.6 & 35 & 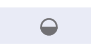 \\
\hline Colorado & 30.7 & 21 & $\bullet$ & 13.9 & 2 & - & 9.7 & 31 & $\bullet$ & 78.8 & 1 & - & 70.1 & 5 & - \\
\hline Connecticut & 38.5 & 2 & - & 17.7 & 6 & 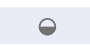 & 6.7 & 3 & - & 73.1 & 12 & $\bullet$ & 67.8 & 13 & - \\
\hline Delaware & 25.0 & 43 & 0 & 18.5 & 13 & $\ominus$ & 10.2 & 38 & $\theta$ & 69.3 & 21 & $\ominus$ & 66.3 & 18 & - \\
\hline District of Columbia & 37.6 & 4 & - & 18.4 & 12 & 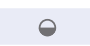 & 8.1 & 15 & $\bullet$ & 54.9 & 51 & 0 & 51.4 & 51 & 0 \\
\hline Florida & 28.8 & 35 & $\ominus$ & 18.6 & 14 & $\bullet$ & 7.5 & 7 & $\bullet$ & 65.1 & 43 & $\ominus$ & 64.3 & 29 & $\ominus$ \\
\hline Georgia & 23.7 & 44 & 0 & 21.1 & 35 & 0 & 11.2 & 46 & 0 & 64.4 & 45 & ○ & 59.4 & 47 & $\ominus$ \\
\hline Hawaii c & 37.9 & 3 & - & 10.2 & 1 & $\bullet$ & 8.2 & 16 & $\ominus$ & 76.4 & 4 & - & 69.4 & 8 & - \\
\hline Idaho & 26.8 & 39 & $\ominus$ & 20.1 & 25 & $\ominus$ & 7.4 & 6 & - & 66.2 & 37 & $\ominus$ & 60.1 & 44 & $\bullet$ \\
\hline Illinois & 28.4 & 36 & $\bullet$ & 19.4 & 21 & $\bullet$ & 9.4 & 29 & $\ominus$ & 65.4 & 42 & $\bullet$ & 58.3 & 48 & $\bullet$ \\
\hline Indiana & 30.1 & 25 & $\ominus$ & 19.9 & 24 & 0 & 10.8 & 43 & $\ominus$ & 64.3 & 46 & 0 & 62.1 & 39 & $\ominus$ \\
\hline lowa & 23.7 & 44 & 0 & 24.0 & 49 & 0 & 8.6 & 19 & $\ominus$ & 74.1 & 10 & $\bullet$ & 68.2 & 11 & - \\
\hline Kansas & 26.1 & 42 & 0 & 20.4 & 28 & $\ominus$ & 9.4 & 29 & $\ominus$ & 68.1 & 26 & 0 & 62.5 & 38 & $\ominus$ \\
\hline Kentucky & 23.0 & 48 & 0 & 20.4 & 28 & $\ominus$ & 12.5 & 48 & 0 & 64.3 & 46 & ○ & 57.7 & 49 & 0 \\
\hline Louisiana & 22.0 & 49 & 0 & 25.6 & 51 & 0 & 9.8 & 33 & $\bullet$ & 68.6 & 24 & ○ & 67.4 & 14 & - \\
\hline Maine & 29.7 & 27 & $\ominus$ & 20.4 & 28 & $\bullet$ & 6.9 & 4 & - & 72.2 & 15 & - & 65.6 & 23 & - \\
\hline Maryland & 33.7 & 11 & - & 23.2 & 44 & 0 & 10.0 & 36 & $\bullet$ & 64.6 & 44 & $\bullet$ & 64.0 & 32 & $\bullet$ \\
\hline Massachusetts & 35.7 & 7 & - & 17.3 & 5 & ○ & 8.0 & 13 & $\ominus$ & 70.6 & 20 & $\bullet$ & 65.3 & 25 & - \\
\hline Michigan & 30.2 & 22 & $\bullet$ & 22.0 & 37 & 0 & 8.5 & 18 & $\ominus$ & 66.9 & 33 & $\ominus$ & 60.0 & 46 & 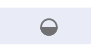 \\
\hline Minnesota & 33.5 & 12 & $\bullet$ & 22.6 & 40 & 0 & 7.1 & 5 & - & 78.3 & 2 & - & 67.9 & 12 & - \\
\hline Mississippi & 19.5 & 51 & 0 & 22.6 & 40 & 0 & 10.4 & 42 & $\ominus$ & 66.9 & 33 & $\bullet$ & 64.5 & 28 & $\bullet$ \\
\hline Missouri & 29.4 & 30 & $\ominus$ & 20.8 & 32 & 0 & 9.8 & 33 & $\ominus$ & 69.1 & 22 & ○ & 67.1 & 15 & - \\
\hline Montana & 30.2 & 22 & $\bullet$ & 17.2 & 4 & $\bullet$ & 9.7 & 31 & $\ominus$ & 72.2 & 15 & - & 71.6 & 1 & - \\
\hline Nebraska & 26.2 & 41 & 0 & 21.7 & 36 & 0 & 7.8 & 9 & - & 75.8 & 5 & - & 65.7 & 22 & - \\
\hline Nevada & 26.8 & 39 & $\bullet$ & 17.7 & 6 & $\ominus$ & 14.5 & 51 & 0 & 59.0 & 50 & 0 & 66.7 & 17 & $\bullet$ \\
\hline New Hampshire & 36.3 & 5 & $\bullet$ & 19.2 & 19 & $\ominus$ & 9.3 & 26 & 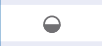 & 70.7 & 19 & $\bullet$ & 66.8 & 16 & - \\
\hline New Jersey & 32.4 & 15 & $\ominus$ & 19.7 & 23 & 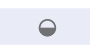 & 9.3 & 26 & $\ominus$ & 67.6 & 29 & $\ominus$ & 64.3 & 29 & $\bullet$ \\
\hline New Mexico & 31.3 & 18 & $\bullet$ & 14.1 & 3 & $\bullet$ & 10.2 & 38 & $\ominus$ & 72.4 & 14 & $\bullet$ & 64.6 & 27 & $\ominus$ \\
\hline New York & 33.8 & 10 & - & 18.7 & 16 & $\ominus$ & 10.9 & 44 & $\ominus$ & 65.9 & 41 & 0 & 63.0 & 37 & $\ominus$ \\
\hline North Carolina & 27.9 & 37 & $\ominus$ & 22.0 & 37 & 0 & 10.2 & 38 & $\ominus$ & 67.0 & 32 & $\ominus$ & 64.3 & 29 & $\ominus$ \\
\hline North Dakota & 32.6 & 14 & $\ominus$ & 23.6 & 47 & 0 & 7.6 & 8 & - & 74.3 & 8 & - & 70.3 & 3 & - \\
\hline Ohio & 31.0 & 20 & $\ominus$ & 23.2 & 44 & 0 & 8.8 & 23 & $\ominus$ & 67.6 & 29 & $\bullet$ & 61.0 & 43 & $\ominus$ \\
\hline Oklahoma & 21.2 & 50 & 0 & 18.1 & 11 & 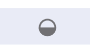 & 10.9 & 44 & 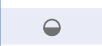 & 75.0 & 7 & - & 70.0 & 6 & - \\
\hline Oregon & 34.0 & 9 & $\bullet$ & 17.7 & 6 & $\ominus$ & 9.1 & 25 & $\ominus$ & 71.0 & 17 & - & 69.4 & 8 & - \\
\hline Pennsylvania & 29.4 & 30 & $\ominus$ & 22.6 & 40 & 0 & 8.0 & 13 & 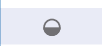 & 63.8 & 49 & 0 & 63.9 & 34 & $\bullet$ \\
\hline Rhode Island & 35.6 & 8 & - & 18.8 & 17 & $\ominus$ & 8.8 & 23 & $\ominus$ & 73.0 & 13 & - & 70.0 & 6 & - \\
\hline South Carolina & 29.7 & 27 & $\ominus$ & 22.5 & 39 & 0 & 8.7 & 21 & 0 & 66.0 & 40 & 0 & 64.0 & 32 & 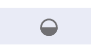 \\
\hline South Dakota & 31.6 & 16 & $\ominus$ & 21.0 & 34 & 0 & 8.6 & 19 & $\ominus$ & 76.9 & 3 & - & 66.2 & 19 & - \\
\hline Tennessee & 29.8 & 26 & $\ominus$ & 20.4 & 28 & $\bullet$ & 13.3 & 50 & 0 & 66.4 & 36 & $\bullet$ & 63.5 & 36 & $\bullet$ \\
\hline Texas & 30.2 & 22 & $\ominus$ & 20.9 & 33 & 0 & 10.3 & 41 & ○ & 67.1 & 31 & $\bullet$ & 61.4 & 42 & $\bullet$ \\
\hline Utah & 29.1 & 33 & $\ominus$ & 20.3 & 27 & 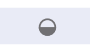 & 4.7 & 1 & - & 75.5 & 6 & - & 65.8 & 20 & - \\
\hline Vermont & 40.2 & 1 & - & 17.7 & 6 & $\ominus$ & 7.9 & 11 & $\bullet$ & 66.6 & 35 & 0 & 65.6 & 23 & - \\
\hline Virginia & 33.5 & 12 & - & 19.6 & 22 & 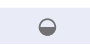 & 8.3 & 17 & 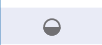 & 68.6 & 24 & 0 & 61.6 & 41 & $\bullet$ \\
\hline Washington & 29.7 & 27 & $\bullet$ & 19.3 & 20 & 0 & 8.7 & 21 & $\bullet$ & 67.9 & 27 & $\ominus$ & 65.8 & 20 & - \\
\hline West Virginia & 23.6 & 47 & 0 & 22.6 & 40 & 0 & 10.0 & 36 & $\bullet$ & 67.9 & 27 & $\ominus$ & 64.7 & 26 & $\bullet$ \\
\hline Wisconsin & 31.3 & 18 & ○ & 23.8 & 48 & 0 & 7.8 & 9 & - & 74.3 & 8 & - & 70.3 & 3 & $\bullet$ \\
\hline Wyoming & 31.4 & 17 & $\ominus$ & 20.2 & 26 & $\ominus$ & 9.8 & 33 & $\ominus$ & 73.8 & 11 & - & 70.7 & 2 & - \\
\hline
\end{tabular}




\begin{tabular}{|c|c|c|c|c|c|c|c|c|c|c|c|c|c|c|c|}
\hline & \multicolumn{3}{|c|}{$\begin{array}{c}\text { Mammogram } \\
\text { in Past } 2 \text { Years } \\
{[\%]} \\
2004\end{array}$} & \multicolumn{3}{|c|}{$\begin{array}{c}\text { Colorectal Cancer } \\
\text { Screening } \\
\qquad \%] \\
2004\end{array}$} & \multicolumn{3}{|c|}{$\begin{array}{c}\text { Up-to-Date on Select } \\
\text { Preventive Services } \\
\text { Men }^{+}(\%) \\
2004\end{array}$} & \multicolumn{3}{|c|}{$\begin{array}{l}\text { Up-to-Date on Select } \\
\text { Preventive Services } \\
\text { Women }{ }^{\dagger}(\%) \\
2004\end{array}$} & \multicolumn{3}{|c|}{$\begin{array}{c}\text { Cholesterol Checked } \\
\text { in Past } 5 \text { Years } \\
(\%) \\
2003\end{array}$} \\
\hline & Data & Rank $^{\ddagger}$ & Grade & Data & Rank & Grade & Data & Rank & Grade & Data & Rank & Grade & Data & Rank & Grade \\
\hline Alabama & 78.1 & 20 & $\ominus$ & 59.9 & 36 & $\ominus$ & 30.3 & 50 & $\ominus$ & 26.9 & 42 & 0 & 88.4 & 42 & 0 \\
\hline Alaska & 67.8 & 50 & 0 & 60.6 & 32 & $\ominus$ & 37.1 & 30 & $\ominus$ & 28.4 & 35 & 0 & 90.3 & 27 & $\ominus$ \\
\hline Arizona & 82.7 & 6 & - & 66.0 & 18 & - & 40.8 & 14 & 0 & 36.2 & 8 & $\bullet$ & 92.2 & 10 & 0 \\
\hline Arkansas & 68.0 & 49 & 0 & 59.0 & 38 & $\ominus$ & 38.8 & 23 & $\bullet$ & 25.6 & 47 & O & 88.6 & 40 & 0 \\
\hline California & 82.8 & 5 & - & 68.1 & 13 & - & 40.0 & 17 & - & 34.8 & 14 & $\bullet$ & 94.6 & 2 & $\bullet$ \\
\hline Colorado & 76.9 & 23 & $\bullet$ & 65.5 & 20 & - & 41.3 & 11 & $\bullet$ & 38.9 & 3 & $\bullet$ & 90.3 & 27 & $\bullet$ \\
\hline Connecticut & 80.4 & 15 & - & 71.4 & 6 & - & 45.4 & 3 & - & 36.2 & 8 & $\ominus$ & 92.7 & 7 & - \\
\hline Delaware & 83.0 & 4 & - & 71.9 & 5 & - & 43.0 & 5 & - & 38.2 & 4 & $\ominus$ & 95.0 & 1 & - \\
\hline District of Columbia & 82.1 & 8 & $\bullet$ & 68.7 & 10 & $\bullet$ & 32.1 & 45 & $\ominus$ & 27.5 & 39 & 0 & 94.0 & 3 & $\bullet$ \\
\hline Florida & 82.3 & 7 & $\bullet$ & 68.3 & 12 & - & 41.8 & 8 & $\bullet$ & 34.6 & 15 & $\bullet$ & 90.6 & 22 & $\ominus$ \\
\hline Georgia & 72.8 & 38 & $\ominus$ & 59.4 & 37 & $\ominus$ & 33.3 & 43 & $\ominus$ & 27.7 & 38 & O & 91.2 & 16 & $\bullet$ \\
\hline Hawaii ç & 84.7 & 2 & $\bullet$ & 35.9 & 51 & O & 20.1 & 51 & 0 & 26.3 & 44 & O & 89.0 & 34 & O \\
\hline Idaho & 69.5 & 48 & 0 & 58.2 & 41 & $\ominus$ & 33.8 & 41 & $\ominus$ & 25.9 & 46 & O & 88.0 & 45 & 0 \\
\hline Illinois & 73.4 & 35 & $\bullet$ & 57.4 & 45 & $\bullet$ & 31.7 & 47 & $\bullet$ & 25.0 & 50 & 0 & 88.2 & 43 & 0 \\
\hline Indiana & 70.3 & 47 & 0 & 58.0 & 42 & $\ominus$ & 35.2 & 39 & $\ominus$ & 25.5 & 48 & O & 91.4 & 15 & $\ominus$ \\
\hline lowa & 73.8 & 33 & $\ominus$ & 62.9 & 27 & - & 38.4 & 26 & $\bullet$ & 34.4 & 17 & $\bullet$ & 90.5 & 24 & $\bullet$ \\
\hline Kansas & 76.9 & 23 & $\ominus$ & 58.8 & 39 & $\ominus$ & 36.9 & 31 & $\ominus$ & 30.7 & 29 & 0 & 88.9 & 36 & 0 \\
\hline Kentucky & 73.9 & 32 & $\bullet$ & 56.3 & 47 & $\ominus$ & 32.4 & 44 & $\ominus$ & 25.1 & 49 & 0 & 87.2 & 49 & 0 \\
\hline Louisiana & 75.0 & 28 & $\ominus$ & 58.7 & 40 & $\ominus$ & 36.8 & 32 & $\ominus$ & 31.2 & 28 & 0 & 86.6 & 51 & 0 \\
\hline Maine & 84.0 & 3 & - & 73.4 & 1 & - & 41.3 & 11 & $\bullet$ & 35.8 & 11 & $\bullet$ & 90.0 & 29 & $\bullet$ \\
\hline Maryland & 82.1 & 8 & $\bullet$ & 72.8 & 3 & - & 42.3 & 7 & - & 34.4 & 17 & $\ominus$ & 92.7 & 7 & - \\
\hline Massachusetts & 81.7 & 10 & - & 68.4 & 11 & - & 35.3 & 37 & $\bullet$ & 34.9 & 13 & $\ominus$ & 93.3 & 4 & $\bullet$ \\
\hline Michigan & 81.3 & 14 & $\bullet$ & 70.5 & 9 & - & 31.5 & 48 & $\bullet$ & 36.5 & 7 & $\ominus$ & 89.9 & 30 & $\ominus$ \\
\hline Minnesota & 81.7 & 10 & $\bullet$ & 73.1 & 2 & $\bullet$ & 41.4 & 10 & $\bullet$ & 47.0 & 1 & - & 90.4 & 26 & $\ominus$ \\
\hline Mississippi & 66.3 & 51 & 0 & 50.2 & 50 & $\bullet$ & 31.1 & 49 & $\ominus$ & 24.7 & 51 & 0 & 88.9 & 36 & 0 \\
\hline Missouri & 71.2 & 45 & 0 & 60.9 & 31 & - & 36.8 & 32 & $\ominus$ & 28.4 & 35 & O & 88.5 & 41 & 0 \\
\hline Montana & 78.3 & 18 & $\ominus$ & 66.1 & 17 & $\bullet$ & 46.0 & 2 & - & 36.0 & 10 & $\bullet$ & 87.6 & 46 & 0 \\
\hline Nebraska & 75.1 & 26 & $\bullet$ & 56.7 & 46 & 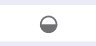 & 36.5 & 34 & $\bullet$ & 31.6 & 26 & O & 87.5 & 47 & O \\
\hline Nevada & 72.7 & 41 & $\bullet$ & 60.5 & 33 & $\ominus$ & 33.8 & 41 & $\bullet$ & 26.1 & 45 & 0 & 89.6 & 31 & $\bullet$ \\
\hline New Hampshire & 81.7 & 10 & $\bullet$ & 71.0 & 8 & - & 41.8 & 8 & - & 33.3 & 20 & $\ominus$ & 91.6 & 12 & $\ominus$ \\
\hline New Jersey & 74.2 & 31 & $\bullet$ & 63.1 & 26 & - & 38.2 & 27 & $\bullet$ & 30.4 & 30 & 0 & 91.2 & 16 & $\ominus$ \\
\hline New Mexico & 71.3 & 44 & 0 & 61.3 & 30 & $\bullet$ & 37.7 & 29 & $\bullet$ & 31.7 & 25 & O & 86.9 & 50 & O \\
\hline New York & 76.9 & 23 & $\ominus$ & 65.5 & 20 & $\bullet$ & 40.3 & 16 & - & 28.9 & 32 & 0 & 90.5 & 24 & $\ominus$ \\
\hline North Carolina & 79.0 & 17 & $\bullet$ & 66.6 & 16 & - & 40.0 & 17 & $\bullet$ & 32.6 & 22 & $\ominus$ & 91.5 & 14 & $\ominus$ \\
\hline North Dakota & 74.7 & 30 & $\bullet$ & 60.5 & 33 & $\ominus$ & 38.9 & 22 & $\ominus$ & 34.6 & 15 & $\bullet$ & 91.1 & 19 & $\ominus$ \\
\hline Ohio & 81.7 & 10 & - & 60.2 & 35 & $\ominus$ & 35.2 & 39 & $\ominus$ & 28.9 & 32 & 0 & 91.0 & 20 & $\ominus$ \\
\hline Oklahoma & 71.2 & 45 & 0 & 55.6 & 48 & $\ominus$ & 40.8 & 14 & - & 28.8 & 34 & 0 & 88.8 & 39 & 0 \\
\hline Oregon & 75.1 & 26 & $\ominus$ & 64.2 & 24 & - & 39.5 & 20 & $\ominus$ & 36.7 & 6 & $\ominus$ & 88.9 & 36 & O \\
\hline Pennsylvania & 72.8 & 38 & $\ominus$ & 62.0 & 29 & $\bullet$ & 35.7 & 36 & $\ominus$ & 27.2 & 41 & 0 & 93.1 & 5 & - \\
\hline Rhode Island & 84.8 & 1 & - & 72.3 & 4 & - & 45.2 & 4 & $\bullet$ & 37.0 & 5 & $\ominus$ & 92.5 & 9 & - \\
\hline South Carolina & 73.5 & 34 & $\bullet$ & 62.1 & 28 & $\bullet$ & 36.5 & 34 & $\ominus$ & 28.1 & 37 & O & 93.1 & 5 & - \\
\hline South Dakota & 79.7 & 16 & - & 64.3 & 23 & - & 42.9 & 6 & - & 35.3 & 12 & $\ominus$ & 89.4 & 32 & $\ominus$ \\
\hline Tennessee & 77.3 & 22 & $\ominus$ & 63.7 & 25 & $\bullet$ & 38.2 & 27 & $\ominus$ & 32.2 & 24 & $\ominus$ & 91.6 & 12 & $\ominus$ \\
\hline Texas & 73.3 & 36 & $\bullet$ & 57.5 & 44 & $\ominus$ & 31.8 & 46 & $\ominus$ & 26.9 & 42 & 0 & 88.2 & 43 & 0 \\
\hline Utah & 73.1 & 37 & $\bullet$ & 65.1 & 22 & $\bullet$ & 41.1 & 13 & - & 31.6 & 26 & 0 & 87.4 & 48 & 0 \\
\hline Vermont & 72.8 & 38 & $\bullet$ & 68.0 & 14 & - & 38.6 & 24 & ○ & 29.9 & 31 & 0 & 90.7 & 21 & ○ \\
\hline Virginia & 75.0 & 28 & $\bullet$ & 65.6 & 19 & $\bullet$ & 39.0 & 21 & $\ominus$ & 32.4 & 23 & $\bullet$ & 90.6 & 22 & $\bullet$ \\
\hline Washington & 77.8 & 21 & $\bullet$ & 67.9 & 15 & $\bullet$ & 38.5 & 25 & $\bullet$ & 34.1 & 19 & ○ & 91.2 & 16 & $\ominus$ \\
\hline West Virginia & 71.5 & 43 & 0 & 55.0 & 49 & $\ominus$ & 35.3 & 37 & $\bullet$ & 27.4 & 40 & 0 & 92.1 & 11 & $\ominus$ \\
\hline Wisconsin & 78.2 & 19 & $\ominus$ & 71.1 & 7 & $\bullet$ & 49.8 & 1 & - & 40.8 & 2 & - & 89.0 & 34 & 0 \\
\hline Wyoming & 72.6 & 42 & $\ominus$ & 57.8 & 43 & $\ominus$ & 40.0 & 17 & $\bullet$ & 32.8 & 21 & $\ominus$ & 89.1 & 33 & 0 \\
\hline
\end{tabular}

* Grades are calculated as tertiles (thirds) and show state performance relative to all other states; $=$ upper third (top performing 33\%), $\bullet=$ middle third (middle $33 \%$ ), $\mathrm{O}=$ lower third (lowest performing 33\%).

Defined in Table 2 .

\& Rankings are based on the relative numeric scores for each indicator, with a ranking of " 1 " indicating the highest rank. When comparing states, we recommend the use of confidence intervals. For this information, please visit the online version of this report at www.cdc.gov/aging.

2003 data are used for all the indicators for Hawaii because no 2004 data exist. 


\section{Using Data for Action at the State and Local Levels}

Many states and communities have developed innovative ways to ensure that important data on the health of older adults is readily available to those who need it for planning programs, setting priorities, and tracking trends. Two of these impressive efforts are taking place at the county level in Orange County, California and at the state level in Missouri.

\section{Condition of Older Adults in Orange County, California}

The growth of Orange County, California's older adult population has outpaced that of the state and the nation, increasing by $27 \%$ versus $14.7 \%$ for the state (California Long Term Care County Data Book 2002). More than 838,000 baby boomers live in Orange County according to the 2000 U.S. Census. While the current population of adults aged 60 and older is

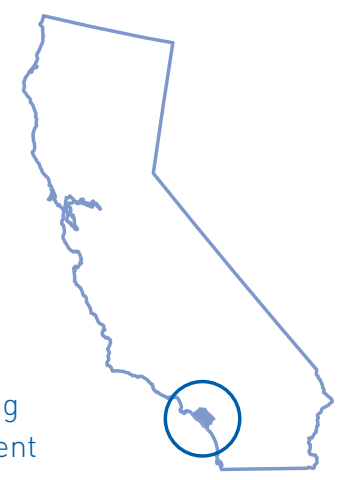
$75 \%$ white (non-Hispanic), the overall population is only $51 \%$ white (non-Hispanic), suggesting that the aging population will be increasingly diverse. Policy makers, service providers, and local community leaders need accurate and detailed information that will help them develop strategies to provide appropriate services for this increasingly diverse population.

In 2002, Orange County launched the Condition of Older Adults report series to provide a comprehensive picture of the general health and well-being of Orange County's older adult population. The document compiles data from a variety of sources, including the nonprofit Orange County Health Needs Assessment lOCHNA http://www.ochna.org), in a user-friendly format for policy makers, professionals, and concerned citizens. The series of reports include information on key indicators and trends in several broad topic areas, such as economics, housing, transportation, civic and social engagement, health status, health risks and behaviors, mental health, and health care. The Condition of Older Adults: 2003 Report, the most recent in the series, took an expanded look at family caregiving, which is an issue of growing importance to older adults, their families, and service providers.

\section{A copy of this report is available at http://www. officeonaging.ocgov.com/demographics.asp.}

Orange County officials understand that balancing needs and resources will be an ever-growing issue as the baby boomer generation ages and adds to the demand for a range of social supports and health services. Finding ways to develop and finance additional service capacity that meets the needs of older adults, allows choice, and ensures quality care will be a challenge for local governments - one that will demand strategic planning, collaboration, and partnership with the broad spectrum of service providers.

\section{Ahead of the Baby Boom: Missouri Prepares}

By 2020, the older adult population in Missouri is expected to exceed 1.2 million or nearly one in five Missouri residents. To prepare for this shift in demographics, state officials have developed the Missouri Senior Report:

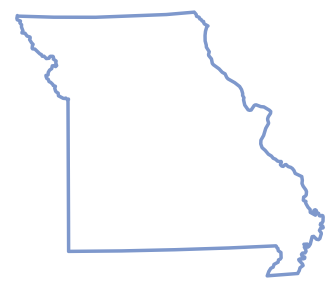
Ahead of the Baby Boom: Missouri Prepares. This 2006 report provides county-level data and other useful information to help state and local policy makers, service providers, and older adults plan for future needs. Prior to this report, national and statelevel data on older adults could only be obtained from multiple sources, and the data were rarely provided in a format that was user-friendly for consumers.

To develop this report, state officials collected input from Missouri's 10 Area Agencies on Aging and from a series of 47 town hall meetings attended by more than 500 residents from around the state. Useful indicators and measures of the status of older adults for the report were identified through these discussions and meetings. The report is available online at http://missouriseniorreport.org/download.shtml.

The report is a collaborative effort of the Missouri Department of Health and Senior Services (DHSS), the Office of Social and Economic Data Analysis (OSEDA) at the University of MissouriColumbia, and other agencies and organizations with an interest in promoting the health and quality of life of older adults. It provides demographic data; rates the state and each county on several key measures; and ranks the counties on the basis of a composite score for all measures. It also includes articles written by academic partners on the topics of mental health, health and socioeconomic disparities, and transportation. DHSS and University of Missouri Extension staff members are available to consult with communities on how to use the data for strategic planning.

The report serves not only as a source of data for planning and policy decisions, but also as a tool for health education and promotion. It provides information about the demographic shifts in the state's population and the need for changes in areas such as housing, transportation, and employment. It will be updated annually and address emerging topics of concern.

To supplement the report, Missouri also has an interactive health data system, Missouri Information for Community Assessment (MICA). This system allows users to summarize data from a variety of sources; create and download tables; prepare geographic presentations; and choose priorities for health policy and planning initiatives based on county and state data. An evidence-based intervention component for selected topics that will enable users to choose interventions to address selected health issues is in development.

The MICA system is available at http://www.dhss.mo.gov/ MICA. 



\section{Fall-Related Morbidity and Mortality}

In 2004, falls were the leading cause of injury deaths among older adults and were responsible for about 14,900, or almost $43 \%$, of all unintentional injury deaths in this age group. Fall-related death rates rose sharply with increasing age and the greatest increase occurred after age 79 . This pattern was similar for men and women, although men were more likely to die from falls than women. Data from CDC's Web-based Injury Statistics and Query Reporting System (WISQARS) show that in 2004, after adjusting for age, the overall fatality rate was $51 \%$ higher for men than for women. ${ }^{(1)}$ The underlying causes for this disparity are unclear. Men may sustain more severe injuries than women because they may fall from greater heights, such as from a ladder; or they may have poorer health from underlying chronic conditions than women of comparable age and thus be less able to survive a fall-related injury. ${ }^{(2)} \mathrm{A}$ recent study found that non-Hispanics consistently had higher fatal fall rates than did Hispanics. ${ }^{(3)}$

\section{Deaths from falls differ by race and state}

In 2004, after adjusting for age, whites had the highest fall death rate (41.4 per 100,000 people aged 65 and older); followed by American Indians and Alaska Natives (25.7 per 100,000 people aged 65 and older); and Asians and Pacific Islanders (25.1 per 100,000 people aged 65 and older). Blacks had the lowest fall death rate (18.2 per 100,000 aged 65 and older) (Figure 9). In addition, the number of fall deaths varied widely among states. In 2004, Alaska reported only seven deaths, while Florida reported 1,236 — the highest number for any state that year. Death rates, which more accurately reflect state differences, also varied widely (Table 4).

\section{Injury from falls most common for older adults}

Falls also are the most common cause of nonfatal injuries and of hospital admissions for trauma among older adults. Ten to $20 \%$ of falls cause serious injuries such as fractures or head traumas. In 2004, over 1.8 million seniors were treated in U.S. hospital emergency departments for fall injuries, and one out of four was subsequently hospitalized. Injury rates increased sharply with age and were four to five times higher among people aged 85 and older than those ages 65 to 74 . Unlike fatality rates, nonfatal fall injury rates for people ages 65 and older were consistently higher for women. After adjusting for age, both the injury rate and the hospitalization rate for women were almost twice that for men. ${ }^{(1)}$

\section{Falls impact mind and body}

Falls can have significant psychological and social consequences. Many older people, whether or not they have fallen, develop a fear of falling. This fear can cause them to limit their activities, which in turn leads to reduced mobility and physical fitness and subsequently to an increased risk of falls. Fear of falling is strongly associated with future falls even among people who have not fallen recently. This fear can lead to deteriorating health, a decline in physical and social functioning, and increased likelihood of admission to a nursing home. ${ }^{(2)}$

FIGURE 9:

In 2004, unintentional deaths from falls among older adults varied widely by race/ethnicity

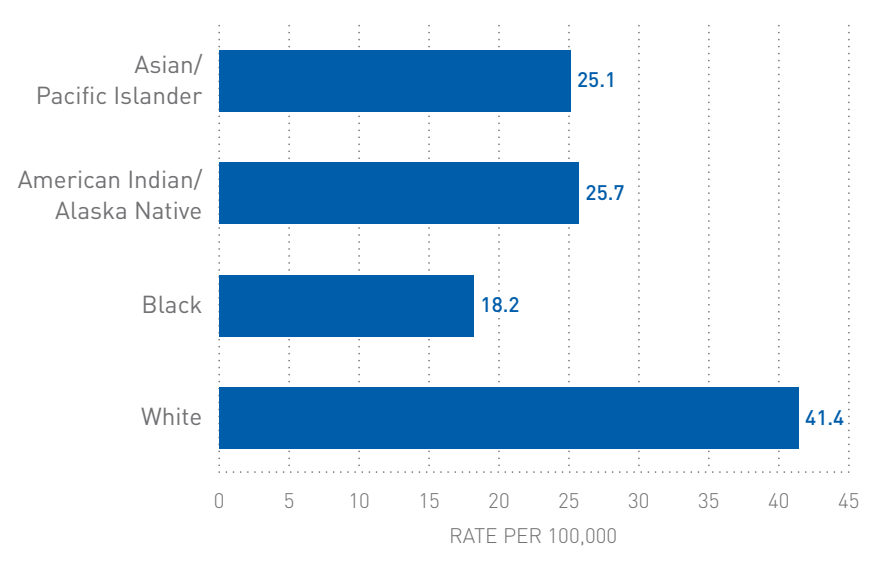

Source: CDC, National Center for Injury Prevention and Control, Web-based Injury Statistics and Query Reporting System (WISQARS), 2006. 
TABLE 4:

A State-by-State View of Unintentional Fall Deaths Among Adults Age 65 or Older, 2004

\begin{tabular}{|c|c|c|c|}
\hline State & $\begin{array}{l}\text { Number of } \\
\text { Deaths }\end{array}$ & $\begin{array}{c}\text { Crude } \\
\text { Death Rate }\end{array}$ & $\begin{array}{l}\text { Age-Adjusted } \\
\text { Death Rate* }\end{array}$ \\
\hline Alabama & 117 & 19.6 & 20.3 \\
\hline Alaska & 7 & $* *$ & $* *$ \\
\hline Arizona & 463 & 62.9 & 64.8 \\
\hline Arkansas & 124 & 32.6 & 32.7 \\
\hline California & 1,228 & 32.2 & 30.8 \\
\hline Colorado & 265 & 58.5 & 58.3 \\
\hline Connecticut & 185 & 39.1 & 32.7 \\
\hline Delaware & 42 & 38.4 & 38.8 \\
\hline District of Columbia & 36 & 53.4 & 51.7 \\
\hline Florida & 1,236 & 42.0 & 40.5 \\
\hline Georgia & 420 & 49.2 & 52.3 \\
\hline Hawaii & 56 & 32.6 & 29.0 \\
\hline Idaho & 94 & 58.9 & 55.6 \\
\hline Illinois & 420 & 27.6 & 26.0 \\
\hline Indiana & 216 & 28.0 & 26.7 \\
\hline lowa & 271 & 62.5 & 53.3 \\
\hline Kansas & 178 & 50.1 & 44.6 \\
\hline Kentucky & 125 & 24.1 & 24.9 \\
\hline Louisiana & 111 & 21.1 & 21.5 \\
\hline Maine & 42 & 22.1 & 20.9 \\
\hline Maryland & 240 & 37.8 & 36.4 \\
\hline Massachusetts & 204 & 23.9 & 21.2 \\
\hline Michigan & 509 & 40.8 & 38.3 \\
\hline Minnesota & 479 & 77.8 & 67.9 \\
\hline Mississippi & 143 & 40.4 & 42.3 \\
\hline Missouri & 468 & 61.0 & 58.4 \\
\hline
\end{tabular}

\begin{tabular}{|c|c|c|c|}
\hline State & $\begin{array}{l}\text { Number of } \\
\text { Deaths }\end{array}$ & $\begin{array}{c}\text { Crude } \\
\text { Death Rate }\end{array}$ & $\begin{array}{c}\text { Age-Adjusted } \\
\text { Death Rate* }\end{array}$ \\
\hline Montana & 82 & 64.7 & 59.0 \\
\hline Nebraska & 141 & 60.6 & 53.4 \\
\hline Nevada & 72 & 27.5 & 32.3 \\
\hline New Hampshire & 74 & 46.7 & 43.9 \\
\hline New Jersey & 263 & 23.4 & 21.9 \\
\hline New Mexico & 203 & 88.4 & 91.6 \\
\hline New York & 794 & 31.8 & 29.4 \\
\hline North Carolina & 480 & 46.4 & 47.6 \\
\hline North Dakota & 68 & 72.8 & 55.5 \\
\hline Ohio & 568 & 37.3 & 35.1 \\
\hline Oklahoma & 157 & 33.8 & 34.4 \\
\hline Oregon & 303 & 65.7 & 58.3 \\
\hline Pennsylvania & 803 & 42.4 & 38.2 \\
\hline Rhode Island & 105 & 69.9 & 56.3 \\
\hline South Carolina & 144 & 27.6 & 28.3 \\
\hline South Dakota & 90 & 82.1 & 68.2 \\
\hline Tennessee & 299 & 40.5 & 42.2 \\
\hline Texas & 803 & 36.1 & 37.6 \\
\hline Utah & 80 & 38.0 & 38.3 \\
\hline Vermont & 85 & 105.1 & 99.4 \\
\hline Virginia & 294 & 34.6 & 34.9 \\
\hline Washington & 459 & 65.1 & 59.6 \\
\hline West Virginia & 131 & 47.2 & 47.9 \\
\hline Wisconsin & 697 & 97.5 & 85.6 \\
\hline Wyoming & 25 & 41.0 & 41.8 \\
\hline TOTAL & 14,899 & 41.0 & 39.2 \\
\hline
\end{tabular}

* Standard population is 2000 , including all races, both sexes.

** Rates based on 20 or fewer deaths may be unreliable,

and thus are not reported here. 


\section{Trends}

As older adults become a larger proportion of the U.S. population, the number of fall injuries can be expected to increase. From 1993 to 2003, the number of people aged 65 and older increased 13\%, from 32.8 million to 36.9 million, while the number of fatal falls more than doubled, from 7,130 to 14,899 . After adjusting for age, fall death rates for both men and women increased about 55\% during this time period and rates were consistently higher for men. ${ }^{(4)}$ The rise in fatal fall rates in part reflects the $37 \%$ increase in the number of people aged 85 and older, who are the fastest growing segment of the older population and the one that is most susceptible to falling. ${ }^{(2)}$

\section{Fractures}

Fractures are among the most prevalent fall injuries. Each year, between 360,000 and 480,000 older adults sustain fall-related fractures. Osteoporosis, a metabolic disease that causes bones to become brittle, greatly increases the chances that a person who falls will suffer a fracture, especially a fracture of the vertebrae, forearm, wrist, or hip. One study found that women with osteoporosis were three times more likely to sustain hip fractures then those without this disease. A 1992 study found that almost $60 \%$ of women ages 70 to 79 and $84 \%$ of women over age 80 had osteoporosis. ${ }^{(5)}$

The most serious and disabling fracture is hip fracture. The majority of hip fractures, up to $95 \%$, are caused by falls, and more than $76 \%$ of hip fractures occur among women. The outcomes of these injuries are extremely serious. Mortality following hip fracture is high - up to $20 \%$ of patients die within a year following their injury. Those who survive often experience significant disability and diminished quality of life. After being hospitalized for about one week, many hip fracture patients are discharged to nursing homes. As many as a quarter of formerly independent older adults remain in nursing homes for at least a year. ${ }^{(2)}$ However, since 1998, hip fracture hospitalization rates among women have declined $17 \%{ }^{(4)}$ In recent years, osteoporosis screening for women and effective treatments to rebuild bone have become widespread, and this public health measure might be reflected in the lower fracture rates. Men tend to have greater bone mass and consequently less risk for hip fractures. However, men do sustain hip fractures, especially after age 80 , and the hip fracture rates among men have not decreased. To counter this trend, screening and osteoporosis treatment might be broadened to include elderly men.

\section{Costs of Fall Injuries}

In 2000, there were almost 10,300 fatal fall injuries and 2.6 million medically treated nonfatal fall-related injuries. Direct medical costs totaled $\$ 0.2$ billion dollars for fatal and $\$ 19$ billion for nonfatal injuries. Of the nonfatal injury costs, $63 \%$ ( $\$ 12$ billion) were for hospitalizations; $21 \%$ ( $\$ 4$ billion) were for emergency department visits; and 16\% (\$3 billion) were for treatment in outpatient settings. Medical expenditures for women, who comprised $58 \%$ of the older adult population, were two to three times higher than for men for all medical treatment settings. Fractures accounted for just 35\% of nonfatal injuries but $61 \%$ of costs. ${ }^{(6)}$ Hip fractures are the most costly fall-related fractures. In 1991, Medicare costs for this injury were estimated to be $\$ 2.9$ billion. The total annual cost of these injuries is projected to reach $\$ 240$ billion by the year 2040. These costs do not account for the long-term consequences of falls, such as disability, functional limitations, decreased productivity, and diminished quality of life. ${ }^{(2)}$

\section{Fall Risk Factors}

Fall risk factors are personal or environmental characteristics that increase a person's chances of falling or of being injured in a fall. The likelihood of falling increases with the number of risk factors present. ${ }^{(2)}$

Personal risk factors include age, functional abilities and some chronic conditions, and can be classified as either modifiable or non-modifiable. Non-modifiable risk factors include older age, a past history of falls, and being female. Factors that are potentially modifiable include lower-body weakness, problems with gait and balance, taking four or more medications or any psychoactive medications, and vision impairment. The presence of certain chronic diseases such as Parkinson's disease, a history of stroke, and arthritis also increase the risk of falls. Although these diseases are not modifiable, identifying and treating symptoms (e.g., reducing arthritis pain and increasing mobility) may reduce the risk of falling. ${ }^{(2)}$

Environmental risk factors may be present in and around the home and in the community. Fall hazards include tripping hazards such as throw rugs and clutter in walkways, lack of stair railings or grab bars, slippery surfaces, unstable furniture and poor lighting. Outdoor hazards include uneven pavement or surfaces, pavement cracks, tree roots, slippery walking surfaces, obstacles in walkways, snow or ice on walkways or steps, and poor lighting. Hazards related to the built environment include poorly maintained buildings and uneven steps; lack of safety features such as handrails, curb cuts, and ramps; and inadequate lighting. ${ }^{(2)}$ 


\section{Making Fall Prevention a Priority: Innovative State Efforts}

\section{Wisconsin's Statewide Fall Prevention Initiative: The Power of Partnership in Action}

Wisconsin's Statewide Fall Prevention Initiative illustrates the power of partnerships in prevention efforts. Wisconsin consistently ranks second highest in the nation in fall deaths. To address this serious problem, in 1999 the Wisconsin Department of Health and Family Services (WI DHFS) launched a fall prevention initiative. Despite a lack of dedicated funding, WI DHFS established this initiative with representatives from the University of Wisconsin; gerontologists and staff from local fall prevention clinics; public health professionals; long term care and aging services; and community groups. In 2002, with the launch of a new health plan for the state, the initiative was formalized as the Statewide Fall Prevention Initiative. The initiative is coordinated by two WI DHFS divisions, Public Health and Disability and Elder Services. Key partners include local, county, and regional aging organizations and health departments; human and social service providers; the University of Wisconsin and the Wisconsin Medical Society.
The initiative has been successful on several fronts. A strong, diverse coalition has been established, and a statewide Fall Prevention Conference was held in 2005. Initiative activities include the development of community-based fall prevention programs and local coalitions to support such programs; promotional

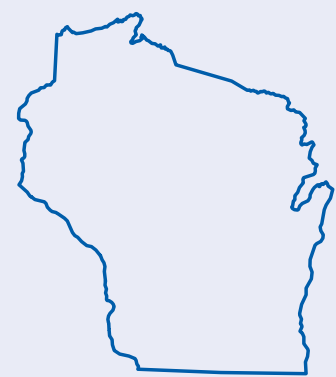
campaigns to encourage older adults to live healthy lifestyles that can reduce the risk of falls; and campaigns to encourage health providers to use evidence-based assessments of their patients' fall risk factors. As a result of the coalition's efforts, Wisconsin's health plan for 2010, Healthiest Wisconsin 2010, included a specific fall prevention objective with short- and long-term outcomes. The state aging plan, Wisconsin State Plan for Serving Older People through the Older Americans Act, made reducing falls and fall deaths a priority. The Wisconsin Medical Society devoted the entire fall 2004 issue of Your Doctor, Your Health to the prevention of falls, and that year's president, Dr. Michael Reineck, devoted his platform to fall prevention among older adults.

\section{Other State Efforts}

Three other very strong state coalitions exist and are leading the way in promoting a variety of fall prevention strategies and initiatives:

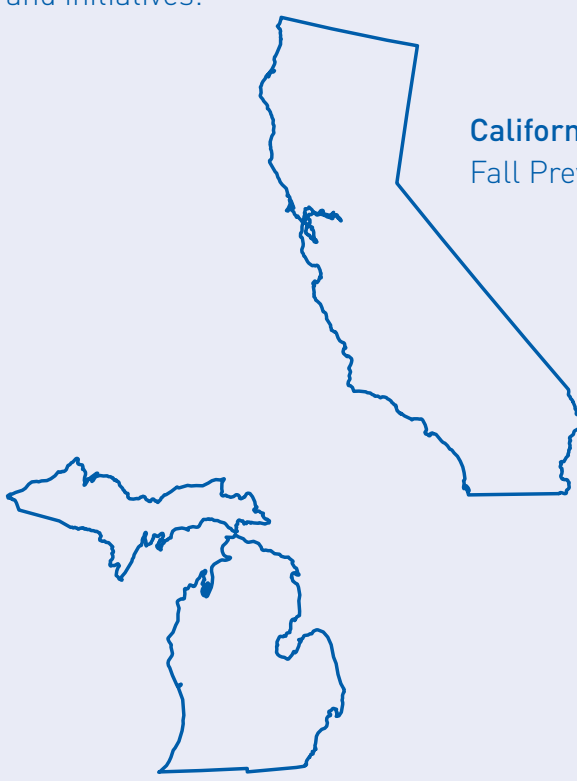

\section{Michigan}

Statewide Fall Prevention Workgroup
These initiatives were created at the state level and were driven by the compelling state-level data about falls and fall-related injuries. Leadership within each of the coalitions has noted the need to have one organizing contact and a small leadership group, but to reach broadly into the community for inclusive coalition membership. Reducing falls and fall-related injuries is often seen as a long-term goal and these states recommend working with shorter term, realistic objectives that can demonstrate progress.

These states also stress the importance of always promoting the issue of fall prevention in the name of the coalition to create an interest in joining, and then connecting members through a leadership listserv. This broad communications strategy keeps community members up-to-date on coalition and research activities. Such strategies facilitate the participation and active involvement of local communities. New Hampshire hosts an annual conference for their broad membership that includes local teams who have worked on specific community or facility projects. Networking and sharing resources among the teams is encouraged.
New Hampshire:

Falls Risk Reduction Task Force 


\section{Reducing Falls: Effective Strategies}

In recent years, research has determined that a number of strategies can reduce falls among older adults: improving leg strength and balance through exercise, managing medications, improving vision, and, when combined with other strategies, modifying the home environment. The most effective preventive measures are multi-component interventions that combine these approaches. ${ }^{(2)}$

\section{The Role of Exercise}

Exercise and physical therapy can address many risk factors that predispose older adults to falling, including lower extremity weakness, generalized deconditioning and poor endurance, musculoskeletal stiffness, slow reaction time to balance disturbances, and slow walking speed. Recent research has shown that overall, exercise interventions can reduce the risk of falling by $12 \%$ and the number of falls by $19 \% .^{(2)}$ Different types of exercise have been found to be effective. These include: Tai Chi, balance and gait training, and strength building. A program of muscle strengthening and balance retraining delivered at home by a trained health professional also has been effective. These exercise interventions have employed a variety of approaches including group classes and individualized in-home programs. ${ }^{(2,7)}$

\section{The Role of Medication Management}

Psychoactive medications, especially benzodiazepines, antidepressants, and sedatives/hypnotics, increase the risk of falling. Many older adults use these types of medications, which can cause changes in mental and physical functioning, dizziness or lightheadedness, balance difficulties, confusion, and sedation. Older adults who show such symptoms should be referred to health professionals for a comprehensive assessment. Physicians should regularly review each patient's medications for potential interactions and side effects that may increase fall risk and where possible, reduce or eliminate medications, or select alternatives. Reducing the number and types of medications, particularly tranquilizers, sleeping pills and anti-anxiety drugs, can be an effective fall prevention strategy when used alone or as part of a multi-component intervention. ${ }^{(2,8)}$

\section{The Role of Environmental Changes}

Home safety: More than half of all injuries among older people occur in and around the home, and the home environment itself is implicated in more than one-third of these falls. ${ }^{(2)}$ Eliminating hazardous conditions (e.g., clutter, poor lighting) and adding supportive features (e.g. grab bars, handrails) on stairs and in bathrooms are important fall prevention strategies. ${ }^{(9)}$ Home assessment and modification may be effective in reducing falls when conducted by trained professionals such as occupational therapists and when focused on those older adults who are at high risk of falling. ${ }^{(2)}$ A number of multi-component interventions that include home modifications have proven effective among individuals with a history of previous falls. ${ }^{(2)}$

Community safety: Outdoor community hazards include uneven pavement or surfaces, pavement cracks, tree roots, slippery walking surfaces, obstacles in walkways and snow or ice on walkways or steps. Hazards related to the built environment include uneven steps and unsafe stair design; lack of safety features such as handrails, grab bars, curb cuts, and ramps; and inadequate lighting. Eliminating existing hazards and designing new communities with fall prevention in mind are strategies that should be pursued. ${ }^{(9)}$

\section{Multi-Component Strategies}

Because falls are frequently caused by the interaction of personal and environmental factors, effective interventions include various components to address multiple risk factors. Reviews of recent research suggest that the most effective intervention strategy uses clinical assessment combined with tailored fall risk-reduction strategies and patient follow-up. Other effective multi-component interventions may incorporate risk factor screening; tailored exercise or physical therapy to improve gait, balance, and strength; medication management; and other elements such as education about fall risk factors; referrals to health care providers for treatment of chronic conditions that may contribute to fall risk; and vision assessment and correction. ${ }^{(2)}$ 


\section{$\gg$ CALL TO ACTION »}

\section{Preventing Falls}

\section{The National Action Plan}

The Falls Free National Action Plan to prevent falls and fallrelated injuries in older adults grew out of a meeting of leading fall prevention experts that was organized by the National Council on Aging's Center for Healthy Aging, with support from the Archstone Foundation and the Home Safety Council. This strategic plan represents a state-of-the-art approach based on the diverse knowledge and experience of more than 58 national organizations, professional associations, and federal agencies that address fall prevention. The National Action Plan, released in March 2005, was developed as both a call to action and a guide for implementing an effective coordinated approach to reducing fall-related injuries and fatal falls among older adults. The 36 strategies and action steps described by the plan could be initiated within an 18-month timeframe, while actual implementation would require an extended time period and a significant commitment of resources.

The contribution and collaboration of multiple and diverse groups - such as consumers, health care providers, policy makers, aging services professionals, representatives of building and construction industries, and community health professionals - will be needed to successfully carry out this plan. When implemented, these strategies will build greater community awareness and support and serve as a foundation for longer-term interventions. More importantly, these strategies will ensure that older adults have fewer falls and fall-related injuries, thereby maximizing their independence and quality of life.

The plan can be found on the Web at http://www.healthyagingprograms.org/resources/ National\%20Action\%20Plan_Final.pdf.

\section{National Action Plan Strategies}

In developing the National Action Plan, participants felt it was essential to address the needs of both older adults and providers across four recognized risk factor areas: physical mobility, medication management, home safety, and community safety. It also was essential to balance the needs of both older adults and providers to ensure equality of supply and demand. For example, creating an awareness campaign may increase the demand for fall prevention services, but not the supply of knowledgeable providers. The cross-cutting goals were an attempt to link providers and the community.
Strategies from the action plan include the following:

Physical mobility:

» Increase awareness among older adults, their caregivers, and health care professionals of factors that can contribute to decline in physical mobility.

» Increase the availability of appropriate physical mobility programs and services for older adults.

Medications management:

» Increase the number of older adults who have annual medication reviews conducted by health care providers or pharmacists and ensure this review includes an adequate focus on falls and fall-related injury prevention, with the goal of reducing or eliminating medications that increase fall risk.

Home safety:

» Raise awareness and disseminate information about home safety practices and options for caregivers and older adults to reduce falls.

\section{Environmental safety in the community:}

» Increase awareness among local, state, and federal policy makers and regulatory officials of the scope and impact of falls and fall-related injuries and death among older adults.

» Focus on sidewalk safety with a clear priority of public environmental safety for older adults.

Cross-cutting issues:

» Improve fall risk management of those at increased risk for falls by promoting coordinated assessment and interventions targeting known fall risk factors.

The Falls Free ${ }^{\text {TM }}$ Coalition was established as a result of this meeting and has since grown with the addition of other key organizations and statewide coalitions. Coalition goals include:

- Promoting collaboration among members;

- Bringing awareness to this issue;

- Publicizing the effectiveness of risk factor identification and intervention; and

- Promoting and facilitating the implementation of the 36 strategies contained within the National Action Plan.

For more information on the coalition, visit http://www.healthyagingprograms.org. 


\section{A Program That Works}

\section{Fear of Falling: A Matter of Balance}

Fear of falling is a common issue among older adults including those who have fallen and those who have not. Older people often restrict their activities because they think it will reduce their risk of falling, but this can actually lead to physical deconditioning and increased fall risk. The Boston University Roybal Center Consortium developed A Matter of Balance, which uses cognitive restructuring techniques and skills training to change perceptions and behaviors in older adults who have limited their activity levels because of fears about falling. The program has been implemented successfully by senior centers, senior housing sites, hospitals, and home health agencies.

A low-cost facilitator's manual and videotape provide a stepby-step implementation guide for practitioners and providers in clinical and community settings. For more information about the program, visit The National Resource Center for Safe Aging at http://www.safeaging.org/model/programs/fearoffalling/ fearoffalling.asp or the Boston University Web site at: http:// www.bu.edu/hdr/products/balance/index.html. ${ }^{(10)}$

Recently, the National Council on the Aging and the Administration on Aging have been working with states to develop and test a "lay leader" model for A Matter of Balance. Initial findings are very promising and published results should be available in the future.

\section{For more information, visit} http://www.mainehealth.org/mh_body.cfm?id=3394.

\section{Selected Additional Resources}

- American Geriatrics Society: Falls in Older Adults Management in Primary Practice

www.americangeriatrics.org/education/falls.shtml

- CDC's National Center for Injury Prevention and Control: Preventing Falls Among Older Adults http://www.cdc.gov/ncipc/duip/preventadultfalls.htm

- Center of Excellence for Fall Prevention www.stopfalls.org

- Home Safety Council: State of Home Safety Facts About Safety in the Home http://homesafetycouncil.org/state_of_home_safety/sohs_2004_p017.pdf

- Practicing Physician Education in Geriatrics Falls Toolkit http://www.gericareonline.net/tools/eng/falls/index.html

- National Center for Patient Safety Falls Toolkit www.patientsafety.gov/SafetyTopics/fallstoolkit/index.html

- National Center for Safe Aging www.safeaging.org/model/default.asp

- National Council on the Aging's Center for Healthy Aging and Falls Free Coalition http://www.healthyagingprograms.com/content.asp?sectionid=113

- National Resource Center on Supportive Housing and Home Modification www.homemods.org

- National Safety Council Fall Prevention Project http://www.nsc.org/issues/healthy_aging.htm

- National Fire Protection Association: Remembering When: A Fire and Fall Prevention Program for Older Adults ${ }^{T M}$ http://www.nfpa.org/categoryList.asp?categorylD=203\&URL=Learning/ Public\%20Education/Programs/Remembering\%20When ${ }^{\mathrm{TM}}$

\section{References}

1. Web-based Injury Statistics Query and Reporting System (WISQARS) (Online). National Center for Injury Prevention and Control, Centers for Disease Control and Prevention (producer). Available from: URL: www.cdc.gov/ncipc/wisqars (accessed Dec. 7, 2006).

2. Stevens JA. Falls among older adults - risk factors and prevention strategies. In Falls Free: Promoting a National Falls Prevention Action Plan. Washington, DC: The National Council on the Aging; 2005.

3. Stevens JA, Dellinger AM. Motor vehicle and fall related deaths among older Americans 1990-98: sex, race, and ethnic disparities. Injury Prevention 2002; 8(4):272-5.

4. Stevens JA, Ryan G, Kresnow M. Fatalities and injuries from falls among older adults-United States, 1993-2003 and 2001-2005. MMWR 2006;55(45):1222-1224.

5. Melton LJ, Chrischilles EA, Cooper C, Lane AW, Riggs BL. How many women have osteoporosis? Journal of Bone and Mineral Research 1992;7(9):1005-10.

6. Stevens JA, Corso PS, Finkelstein EA, Miller TR. Cost of Fatal and Nonfatal Falls among Older Adults. Injury Prevention 2006; 12(5):290-295.

7. Rose DF. The role of exercise in reducing falls and fall-related injuries in older adults. In Falls Free: Promoting a National Falls Prevention Action Plan. Washington, DC: The National Council on the Aging; 2005.

8. Cameron KA. The role of medication modification in fall prevention. In Falls Free: Promoting a National Falls Prevention Action Plan. Washington, DC: The National Council on the Aging; 2005.

9. Pynoos J, Sabata D, Choi IH. The role of the environment in fall prevention at home and in the community. In Falls Free: Promoting a National Falls Prevention Action Plan. Washington, DC: The National Council on the Aging; 2005.

10. Tennstedt S, Howland J, Lachman M, Peterson E, Kasten L, Jette A. A randomized, controlled trial of a group intervention to reduce fear of falling and associated activity restriction in older adults. Journals of Gerontology Series B- Psychological Sciences \& Social Sciences. 53(6):P384-92, 1998 Nov. 


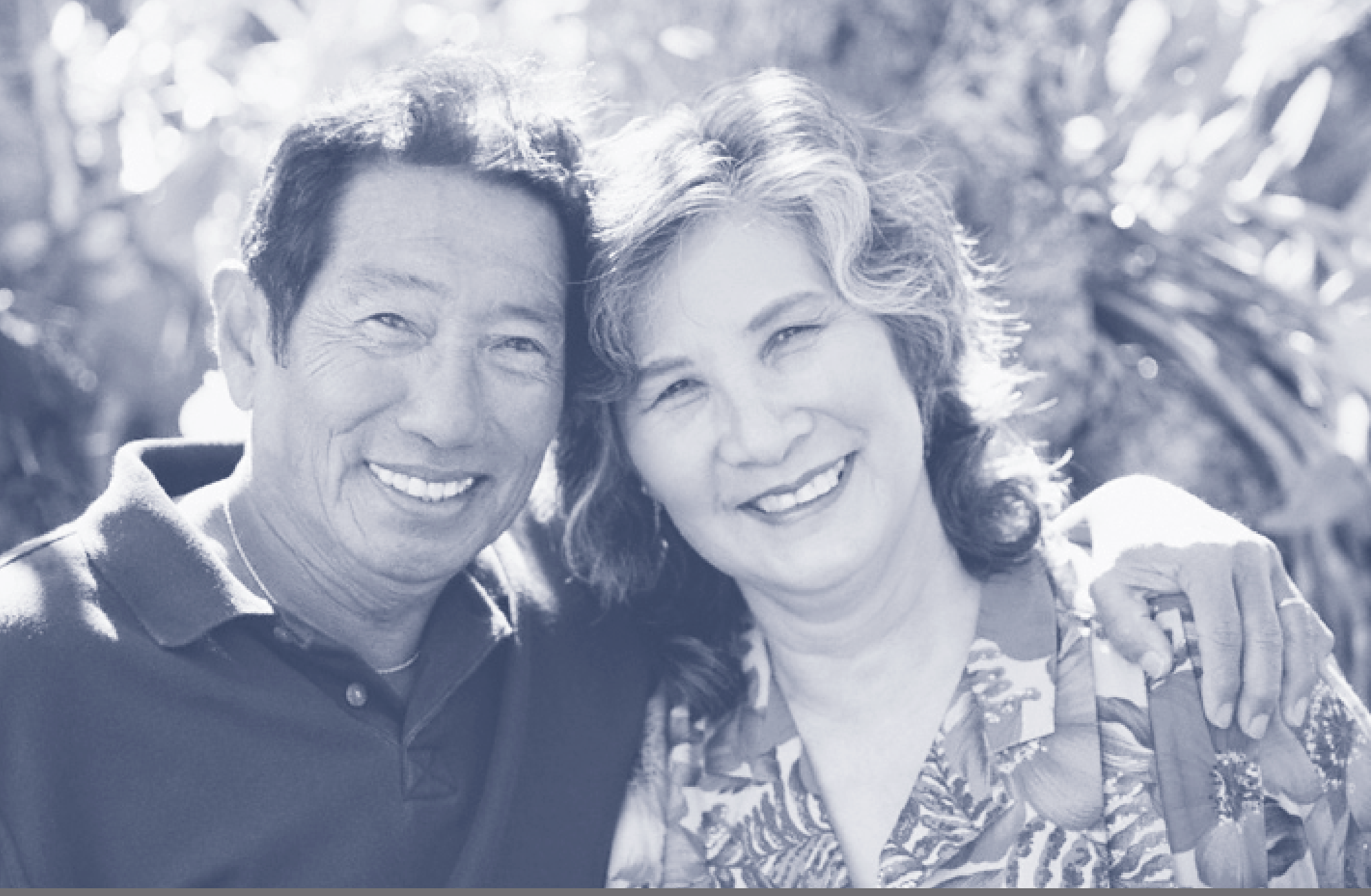

\section{Appendix}

\section{Healthy People 2010 Objectives}

Healthy People 2010 objectives are national health goals for the United States to achieve over the first decade of the new century. These objectives set specific targets to help guide states, communities, professional organizations, and others in developing programs to improve health for all Americans. Healthy People 2010 objectives and targets were developed in consultation with a wide range of experts on the basis of the best available and most current scientific knowledge. In this report, the 15 indicators used to assess the health of adults aged 65 or older are based on the Healthy People 2010 targets. 
TABLE 5

\section{Report Card Indicators and Healthy People 2010 Targets}

\begin{tabular}{|c|c|}
\hline Indicator & Healthy People 2010 Target \\
\hline \multicolumn{2}{|l|}{ Health Status } \\
\hline 1. Physically unhealthy days & No target specified. \\
\hline 2. Frequent mental distress & No target specified. \\
\hline 3. Oral health: complete tooth loss & $\begin{array}{l}\text { No more than } 20 \% \text { of adults aged } 65 \text { years or older who have lost all of their } \\
\text { natural teeth. }\end{array}$ \\
\hline 4. Disability & No target specified. \\
\hline \multicolumn{2}{|l|}{ Health Behavior } \\
\hline $\begin{array}{l}\text { 5. No leisure-time physical activity } \\
\text { in past month }\end{array}$ & $\begin{array}{l}\text { No more than } 20 \% \text { of adults aged } 18 \text { years or older with no leisure-time } \\
\text { physical activity. }\end{array}$ \\
\hline \multirow{2}{*}{$\begin{array}{l}\text { 6. Eating } \geq \text { five servings of } \\
\text { fruits and vegetables daily }\end{array}$} & $\begin{array}{l}\text { At least } 75 \% \text { of people aged } 2 \text { years or older who consume at least two daily } \\
\text { servings of fruit. }\end{array}$ \\
\hline & $\begin{array}{l}\text { At least } 50 \% \text { of people aged } 2 \text { years or older who consume at least three daily } \\
\text { servings of vegetables, with at least one-third of these servings being dark green } \\
\text { or orange vegetables. }\end{array}$ \\
\hline 7. Obesity & No more than $15 \%$ of adults aged 20 years or older who are obese. \\
\hline 8. Current smoking & No more than $12 \%$ of adults aged 18 years or older who smoke. \\
\hline \multicolumn{2}{|l|}{ Preventive Care and Screening } \\
\hline 9. Flu vaccine in past year & $\begin{array}{l}\text { At least } 90 \% \text { of adults aged } 65 \text { years or older who had a flu shot } \\
\text { within the past year. }\end{array}$ \\
\hline 10. Ever had pneumonia vaccine & $\begin{array}{l}\text { At least } 90 \% \text { of adults aged } 65 \text { years or older who have ever received a } \\
\text { pneumonia vaccine. }\end{array}$ \\
\hline 11. Mammogram within past two years & $\begin{array}{l}\text { At least } 70 \% \text { of women aged } 40 \text { years or older who had a mammogram } \\
\text { within the past two years. }\end{array}$ \\
\hline 12. Ever had colorectal screening & $\begin{array}{l}\text { At least } 50 \% \text { of adults aged } 50 \text { years or older who have ever received a } \\
\text { sigmoidoscopy. }\end{array}$ \\
\hline $\begin{array}{l}\text { 13. Up-to-date on selected } \\
\text { preventive services }\end{array}$ & No target specified. \\
\hline $\begin{array}{l}\text { 14. Cholesterol checked } \\
\text { within past five years }\end{array}$ & $\begin{array}{l}\text { At least } 80 \% \text { the proportion of adults aged } 18 \text { years or older who have had their } \\
\text { cholesterol checked in the past five years. }\end{array}$ \\
\hline \multicolumn{2}{|l|}{ Injuries } \\
\hline 15. Hip fractures & $\begin{array}{l}\text { No more than } 416 \text { hospitalizations per } 100,000 \text { persons aged } 65 \text { years or older for } \\
\text { women and no more than } 474 \text { for men. }\end{array}$ \\
\hline
\end{tabular}




\section{Major Data Sources and} Technical Information

\section{Behavioral Risk Factor Surveillance System}

For the past two decades, CDC's Behavioral Risk Factor Surveillance System (BRFSS) has helped states survey U.S. adults regarding a wide range of personal behaviors that affect their health. The BRFSS focuses primarily on physical activity; nutrition; tobacco use; and use of proven preventive services (such as cancer screenings). All of these factors can have a tremendous impact on the rates of the nation's leading health-related causes of death. BRFSS survey questions assess how many people engage in these and other health and risk behaviors, whether these behaviors are increasing over time, and which populations might be most at risk. The crucial information gathered through this state-based telephone survey system is used by national, state and local public health agencies to monitor the need for and the effectiveness of various public health interventions.

Although the BRFSS is one of our most useful tools for assessing the health of the older adult population, it has at least three limitations. First, it excludes people who do not have telephones or who live in institutions such as nursing homes. Second, it may underrepresent people who are severely impaired because they lack the functional capacity required to participate in the survey. Third, all responses to the BRFSS are self-reported and therefore have not been confirmed by a health care provider.

The BRFSS is administered and supported by the Division of Adult and Community Health, National Center for Chronic Disease Prevention and Health Promotion, CDC.

For more information, visit http://www.cdc.gov/brfss.

\section{National Hospital Discharge Survey}

The National Hospital Discharge Survey (NHDS), which has been conducted annually since 1965, gathers information on characteristics of inpatients discharged from nonfederal short-stay hospitals in the United States. The NHDS collects data from approximately 270,000 inpatient records from a national sample of about 500 hospitals. The survey covers only hospitals with an average length of stay of fewer than 30 days for all patients, general hospitals, and children's general hospitals. It excludes federal, military, and Department of Veterans Affairs hospitals, as well as hospital units of institutions (such as prison hospitals) and hospitals with fewer than six patient beds.

The NHDS is administered and supported by the Hospital Care Statistics Branch, National Center for Health Statistics, CDC. Data are disseminated annually through published documents; public-use data tapes; data diskettes; CD-ROMs; and downloadable files.

For more information, visit http://www.cdc.gov/nchs/ about/major/hdasd/nhds.htm.

\section{Data Warehouse on Trends in Health and Aging}

With support from the National Institute on Aging, CDC's National Center for Health Statistics (NCHS) created the Data Warehouse on Trends in Health and Aging, a Web-based, userfriendly tool that provides access to up-to-date information on the health of older Americans. The Data Warehouse is a collection of data tables that provide information on trends in health-related behaviors, health status, health care use, and health care costs among older adults. The system includes a data dissemination tool called Beyond $20 / 20^{\circ}$ that allows users to retrieve and display customized tables of health information on older men and women of various ages, races, and ethnicities.

For more information, visit http://www.cdc.gov/nchs/ agingact.htm.

\section{WISQARS ${ }^{\text {TM }}$ (Web-based Injury Statistics Query and Reporting Systeml}

WISQARS $^{\mathrm{TM}}$ is CDC's National Center for Injury Prevention and Control's interactive, online database that provides customized injury-related mortality data and nonfatal injury data. This data is useful for research and for making informed public health decisions.

Mortality reports are based on data from U.S. death certificates, and nonfatal reports are based on data from a representative sample of nonfatal injuries treated in U.S. hospital emergency departments. All reports can provide a statistical table about a particular injury's cause and other user-specified details, such as age range and sex.

For more information and an on-line tutorial, visit http:// www.cdc.gov/ncipc/wisqars/default.htm. 


\author{
Acknowledgements \\ Advisory Board Members \\ David Baldridge, PhD \\ Executive Director \\ American Association for \\ International Aging \\ William F. Benson \\ Principal \\ Health Benefits ABCs \\ Yanira Cruz, MPH \\ President and CEO \\ The National Hispanic Council \\ on Aging \\ Karyne Jones \\ President and CEO \\ The National Caucus and \\ Center on Black Aged \\ Bob Meyers \\ President \\ National Press Foundation \\ Judy Salerno, MD, MS \\ Deputy Director \\ National Institute on Aging, \\ National Institutes of Health \\ Mary E. Tinetti, MD \\ Director \\ Yale Program on Aging
}

\author{
Project Co-Directors \\ Margaret J. Moore, MPH \\ Public Health Advisor \\ Centers for Disease Control \\ and Prevention \\ Andrée C. Harris \\ Public Health Analyst \\ Centers for Disease Control \\ and Prevention \\ Leslie M. Hardy, MHS \\ Vice President \\ The Merck Company Foundation \\ Michele Patrick, MGA \\ Consultant
}

\section{Principal Writers}

Lisa Jeannotte, MA

Consultant

Margaret J. Moore, MPH

Public Health Advisor

Centers for Disease Control

and Prevention
Falls Working Group Members

Bonita Lynn Beattie, PT, MPT, MHA

Vice President

Research and Demonstrations

National Council on Aging

Catherine Gordon

Senior Public Health Analyst

Centers for Disease Control

and Prevention

Margaret J. Moore, MPH

Public Health Advisor

Centers for Disease Control

and Prevention

Judy A. Stevens, PhD

Epidemiologist

Centers for Disease Control

and Prevention

Special thanks to:

CDC Foundation
Contributors

Barb Alberson, MPH

Bill Elder, PhD

Tracy Ellingson

Anne Esdale, MPH

Helen Grange

Linda Hale

Julie D. Kosteas, MPH

Tricia Schlechte

Rhonda Siegel

Centers for Disease Control and Prevention

Lindsay Abraham, MPH

Lynda A. Anderson, PhD

Brian Armour, PhD

Julie Bolen, PhD, MPH

Cynthia Crocker

Amanda Crowell

Kristine Day, MPH

Clark Denny, PhD

Cynthia Gelb

Barbara F. Gooch, DMD, MPH

Cheryl Holiness, MS

Rosemarie Kobau, MPH

Judy Kruger, PhD, MS

Jason E. Lang, MPH, MS

Louise Murphy, PhD

Sarah O'Leary, MPH, MA

Stephanie Ramsey, MS

Jaya Rao, MD, MHS

Judy A. Stevens, PhD

Kristina Theis, MPH

Sherry Williams, MPH, CHES

Hatice Sahin Zahran, MD, MPH

An interactive version of The State of Aging and Health in America 2007 report is available online at www.cdc.gov/aging.

\section{Resources for Journalists}

CDC has partnered with the American Society on Aging (ASA) to create background material for the media on several topics related to older adult health, ranging from West Nile Virus to epilepsy. These materials are available at http://www.asaging.org/media/cdc.cfm. Topics related to this report include the following:

- Cognitive Health

- Disability
- Physical Activity

- Immunizations
- Heart Disease

- Fall Prevention

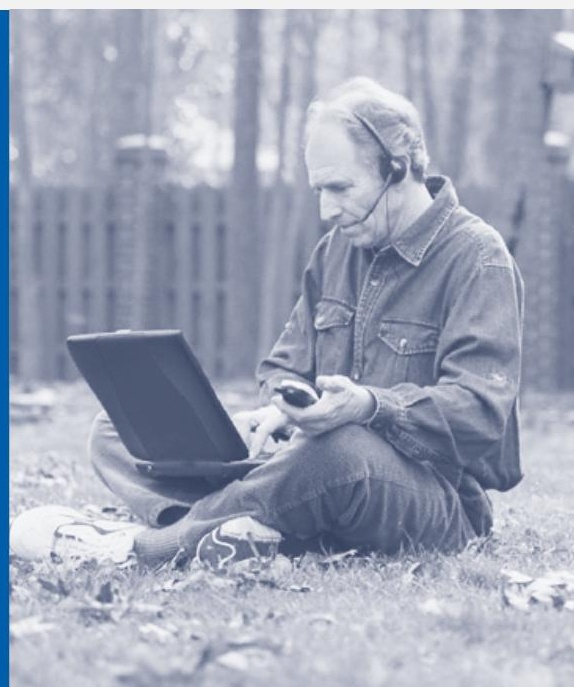




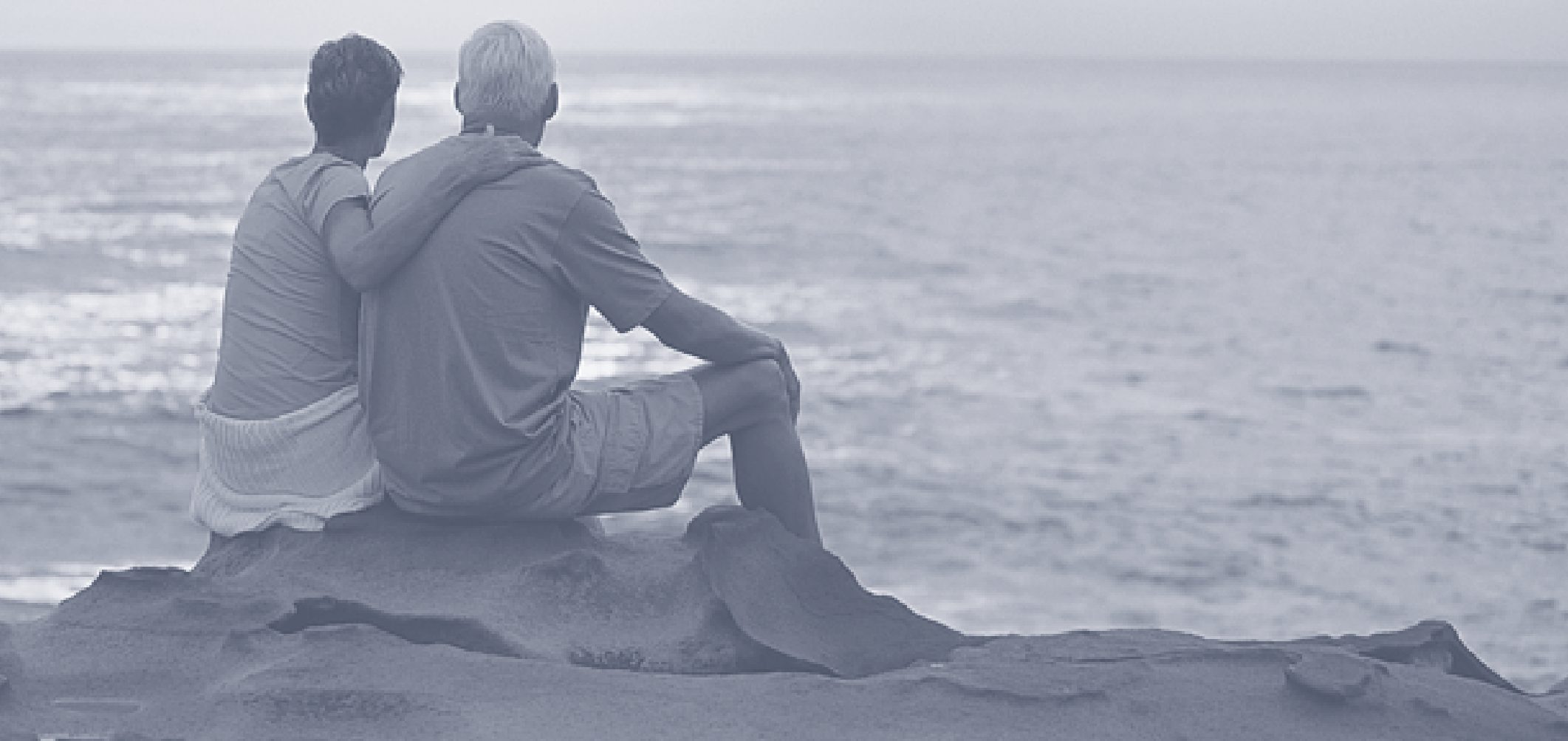

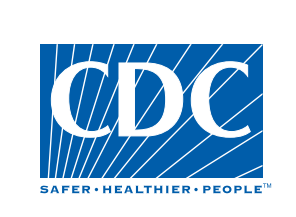

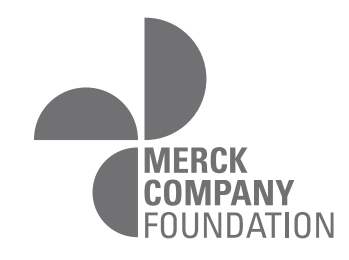

\section{Centers for Disease Control and Prevention}

The Centers for Disease Control and Prevention, as the sentinel for the health of people in the United States and throughout the world, strives to protect people's health and safety, provide reliable health information, and improve health through strong partnerships. CDC's mission is to promote health and quality of life by preventing and controlling disease, injury, and disability.

\section{The Merck Company Foundation}

2007 marks the 50th anniversary of The Merck Company Foundation, a U.S.-based, private charitable foundation. Established in 1957 by the global research-driven pharmaceutical company Merck \& Co., Inc., the Foundation is funded entirely by the Company and is Merck's chief source of funding support to qualified non-profit, charitable organizations.

www.cdc.gov/aging www.merck.com/cr 